\title{
Modelling of Endothelial Cell Migration and Angiogenesis in Microfluidic Cell Culture Systems
}

\author{
by
}

Nikola Kuzmic

\begin{abstract}
A thesis submitted in conformity with the requirements for the degree of Master of Applied Science

Department of Mechanical \& Industrial Engineering University of Toronto
\end{abstract}

(c) Copyright by Nikola Kuzmic (2018) 


\title{
Modelling of Endothelial Cell Migration and Angiogenesis in Microfluidic Cell Culture Systems
}

\author{
Nikola Kuzmic \\ Master of Applied Science \\ Department of Mechanical \& Industrial Engineering \\ University of Toronto
}

2018

\begin{abstract}
Tumour-induced angiogenesis involves growth of new blood vessels from existing vasculature in response to signals induced by the undernourished part of tumour tissue. Due to high costs and ethical issues associated with in vivo experiments, significant efforts have been undertaken to develop computational models and physiologically relevant $3 \mathrm{D}$ in vitro assays to study angiogenesis in a highly controllable and accessible manner. Our goal was to utilize existing modelling techniques and apply them to an in vitro environment to model endothelial cell (EC) migration and angiogenesis inside the tubeless microfluidic angiogenesis assay. Here we leverage two continuum models which are implemented using the Method of Lines and discretized in space using the finite difference approximation. The aim was to simulate EC angiogenic response under different VEGF concentrations and investigate microfluidic device geometry as a potential parameter that can accelerate angiogenesis.
\end{abstract}




\section{Acknowledgments}

I dedicate this work

to my Mom and Dad.

I sincerely thank Edmond Young for all his guidance, help and support. Besides having endless patience throughout my thesis, Edmond taught me how to persevere in the face of obstacles and served as a mentor to me in many ways. I would also like to thank Thomas Moore for his help with simulations, Deepika Devadas and Noosheen Walji for teaching me about cell culture experiments as well as the rest of Young Lab for all their help. In addition, I would like to thank David Steinman and Lidan You for their guidance and agreeing to be on my thesis committee.

Finally, I would like to acknowledge NSERC - Canada Graduate Scholarship (CGSM), Ontario Graduate Scholarship (OGS), M.A.Sc. Entrance Award, Barbara and Frank Milligan Graduate Fellowship, Weber and Mariano Graduate Scholarship, as well as funding from the Mechanical and Industrial Engineering Department at the University of Toronto without which I would not have been able to complete this thesis. 


\section{Table of Contents}

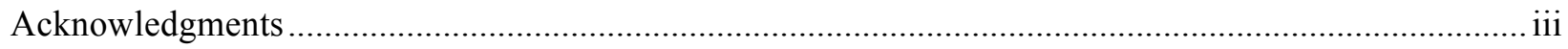

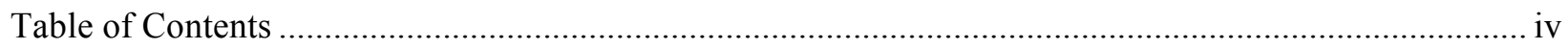

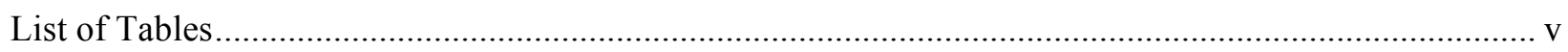

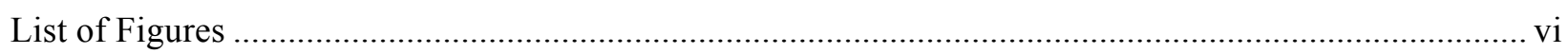

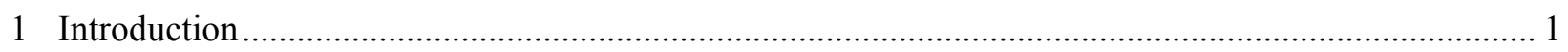

2 Background and Literature Review - Mathematical Modelling of Cell Migration and

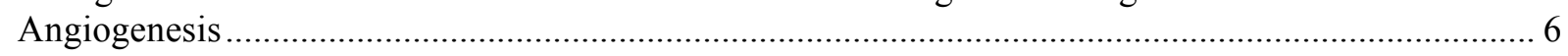

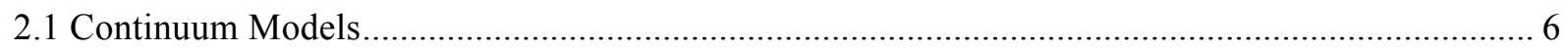

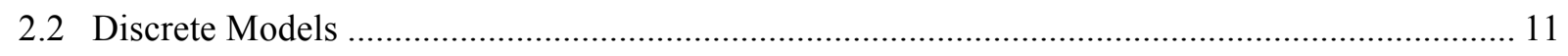

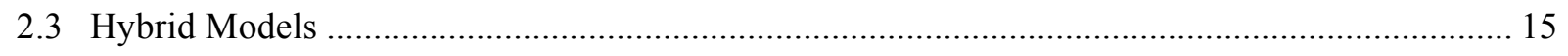

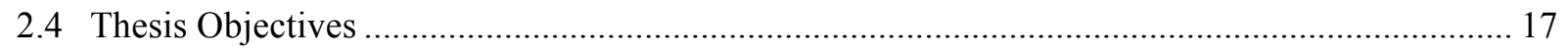

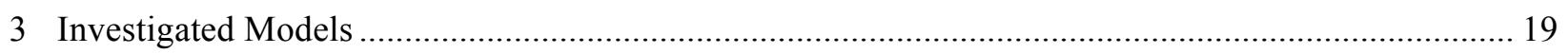

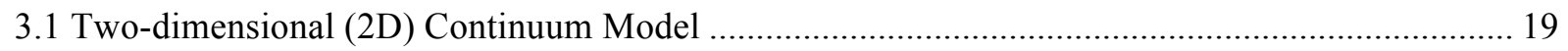

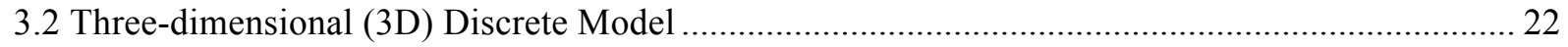

4 Integration of Computational Modelling with Microfluidic Cell Culture Experiments ...................... 26

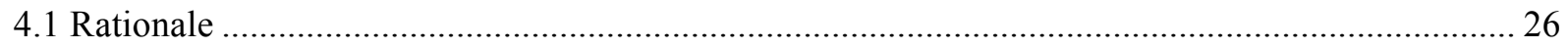

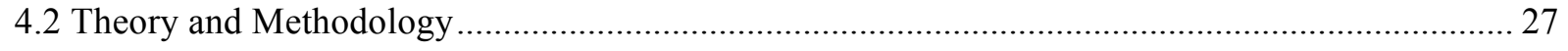

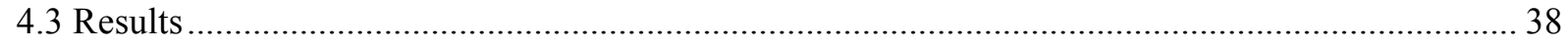

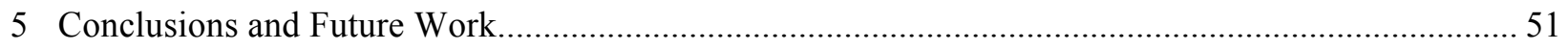

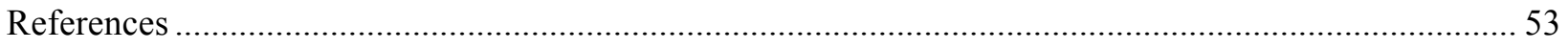

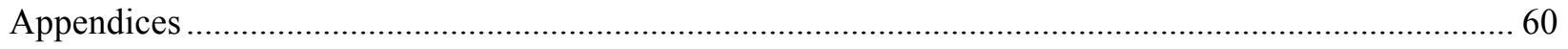

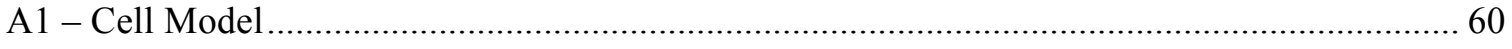

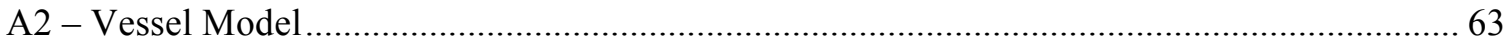




\section{List of Tables}

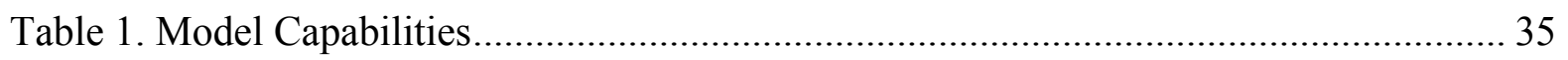

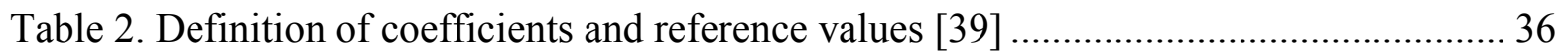

Table 3. Characteristic values used for non-dimensionalization of the cell and vessel

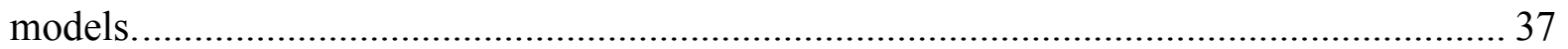




\section{List of Figures}

Figure 1.1. Angiogenesis process. Undernourished tumour tissue secretes angiogenic factors which signal the initially quiescent vessel to start proliferating. Endothelial cells that line the vessel wall differentiate into tip and stalk cells and subsequently follow the increasing growth factor gradients. As the newly formed vessels proliferate towards the tumour, they can branch, fuse together (anastomise) or regress. [5]

Figure 2.1. Continuum models. Cell density propagation from the right towards the tumour implant on the left [29] (Reproduced with permission from Elsevier). Endothelial cell distribution following the TAF gradient $\mathrm{c}=1-\mathrm{y}$ [31] (Reproduced with permission from Oxford University Press). Vascular network formation [38] (Reproduced with permission from American Physical Society).

Figure 2.2. Discrete models. Angiogenesis with moderate chemotactic response under attractant source [40] (Reproduced with permission from Elsevier). Angiogenesis simulations illustrating initial tip/stalk pattern selection [44] (Reproduced with permission from PLOS Computational Biology). Simulations and experimental angiogenesis results [52] (Reproduced with permission from The Royal Society).

Figure 2.3. Hybrid models. Growth of capillary network [53] (Reproduced with permission from PLOS One). Tumour induced angiogenesis [54] (Reproduced with permission from The Royal Society)...

Figure 3.1 Initial development of Anderson and Chaplain's model [32]. (a) Steadystate VEGF distribution. (b) Linear steady-state FN distribution. (c) Initial EC distribution. Red indicates high and blue indicates low EC density. (d) EC migration due to VEGF and $\mathrm{FN}$ gradient at $\mathrm{t}=1.125$ days .

Figure 3.2 Angiogenesis simulations created by open-source software Microvessel CHASTE [56] inside the diffusion port geometry $(100 \times 100 \times 320 \mu \mathrm{m})$. (a) Initial parent vessel used to represent seeded ECs in the left channel and source of VEGF from the right channel. (b) Vessel growth at $\mathrm{t}=1$ day. (c) Vessel growth at $\mathrm{t}=2$ days.

Figure 4.1. Microfluidic device geometry, nomenclature, and general methodology. (a) Image of microfluidic device used to study cancer cell migration and angiogenesis (scale bar $\sim 5 \mathrm{~mm}$ ). Device consists of 2 x 2 array of microfluidic cell culture systems. (b) Geometry of single microfluidic cell culture system, consisting of left and right microchannels and interconnecting migration channels. This geometry was employed for our 3D COMSOL simulations. (c) Plot of VEGF concentration in 3D microfluidic system after $24 \mathrm{~h}$ of diffusion from VEGF source. (d) Outline of microfluidic system showing location $\left(x^{\prime}=1\right.$; red point) where VEGF concentration is exported every 15 min and imposed as time-dependent Dirichlet boundary condition in our 1D mathematical models. (e) VEGF concentration at $x^{\prime}=1$ over 24 h. (f) Top view projection of 3D domain. Inset illustrates the domain of interest for our 1D mathematical models ( $\mathrm{x}$ '-axis is horizontal direction). 
Figure 4.2. Cell migration and angiogenic sprouting as predicted using the cell and vessel models, respectively. Cell model results for (a) $t=0$, (b) $t=12 \mathrm{~h}$, and (c) $t=24$ $\mathrm{h}$. Vessel model results for (d) $t=0$, (e) $t=12 \mathrm{~h}$, and (f) $t=24 \mathrm{~h}$. Illustrations are included to visually represent and help interpretation of the graphs. ECs are shown in blue, dead cells are shown in red (for d, e, and f only). Hydrogel regions are grey, channels filled with media are pink, and the VEGF gradient is shown as green. Graphs show EC density $\left(n^{\prime}\right)$ and VEGF concentration $\left(c^{\prime}\right)$ for the cell model, and sprout tip density $\left(n^{\prime}\right)$, vessel length density $\left(\rho^{\prime}\right)$ and VEGF concentration $\left(v^{\prime}\right)$ for the vessel model, all as dimensionless quantities. Distance is represented by a dimensionless $x$ 'axis.

Figure 4.3. Experimental data fitted with both the cell and vessel models. (Dotted lines) EC density of the cell model; (solid lines) vessel length density of the vessel model; (filled data points) experimental data. VEGF concentrations tested included: 30 $\mathrm{ng} / \mathrm{mL}$ (blue), $100 \mathrm{ng} / \mathrm{mL}$ (red), and $500 \mathrm{ng} / \mathrm{mL}$ (purple), and all results represent 24-h periods.

Figure 4.4. Adjusted geometries: changes in migration port width (a-c) and length (df). (c) VEGF concentration profiles over $24 \mathrm{~h}$, at $\mathrm{x}^{\prime}=1$ for different widths. (f) VEGF concentration profiles over $24 \mathrm{~h}$, at $\mathrm{x}^{\prime}=1$ for different lengths.

Figure 4.5. Changing widths with the cell model. Cell model chemotactic migration simulations for different migration port widths $\left(w^{\prime}=0.5,1.0\right.$ and 1.5$)$ occurring over $24 \mathrm{~h}$ with VEGF concentration at $500 \mathrm{ng} / \mathrm{mL}$.

Figure 4.6. Changing widths with the vessel model. Vessel model simulations for different migration port widths ( $\mathrm{w}^{\prime}=0.5,1.0$ and 1.5 ) occurring over $24 \mathrm{~h}$ with VEGF concentration at $500 \mathrm{ng} / \mathrm{mL}$.

Figure 4.7. Changing lengths with the cell model. Cell model simulations for different migration port lengths ( $l^{\prime}=0.75,1.0$ and 1.5$)$ occurring over $24 \mathrm{~h}$ with VEGF concentration at $500 \mathrm{ng} / \mathrm{mL}$.

Figure 4.8. Changing lengths with the vessel model. Vessel model simulations for different migration port lengths $\left(l^{\prime}=0.75,1.0\right.$ and 1.5$)$ occurring over $24 \mathrm{~h}$ with VEGF concentration at $500 \mathrm{ng} / \mathrm{mL}$.

Figure 4.9. Assessing geometric features potential to enhance angiogenesis. Three different diffusion port widths (top) and lengths (bottom). 


\section{Chapter 1}

\section{Introduction}

Angiogenesis is the growth or extension of new blood vessels from existing vasculature, and can occur in normal physiological processes such as wound healing and embryogenesis, or in disease processes such as tumour development. Tumour angiogenesis occurs in response to secretion of soluble factors from tumour sites at a stage when diffusion of oxygen and other nutrients from the local vasculature becomes insufficient to nourish the central region of the tumour. As a result, the central region becomes hypoxic, resulting in cell death and development of a necrotic core. For the tumour to continue its growth, tumour cells secrete various growth factors including vascular endothelial growth factor (VEGF) and fibroblast growth factor (FGF), which induce tumour cell proliferation and aid in the recruitment of new blood vessels [1]. When pro- and anti-angiogenic factors are imbalanced in favour of pro-angiogenic factors, the angiogenic switch is activated, and endothelial cells (ECs) that line the vasculature differentiate into tip and stalk endothelial cells [2]. Tip endothelial cells

sense and respond to tumour-generated chemokine gradients by migrating into and invading the nearby stroma, while stalk cells enable expansion of the vessels and possess elevated proliferative capacity - process referred to as chemotaxis. Another well-established angiogenesis process is haptotaxis. It involves migration of ECs along an adhesive chemical gradient, such as fibronectin (FN). As ECs move through the extracellular matrix (ECM) they bind to FN macromolecules via cell-surface receptors. Although the character of the vascular network within the tumour is critical to tumour development [3], migration of tip endothelial cells is often viewed as the governing mechanism of tumour angiogenesis, and 
thus migration and angiogenesis are associated processes. To date, our understanding of how growth factors ultimately drive angiogenesis remains incomplete. Advancing our fundamental knowledge of the mechanisms of cell migration and angiogenesis is critical to understanding tumour development, improving cancer therapy, and accelerating drug discovery [4]. Illustrated below are the key steps involved in angiogenesis (Figure 1.1).

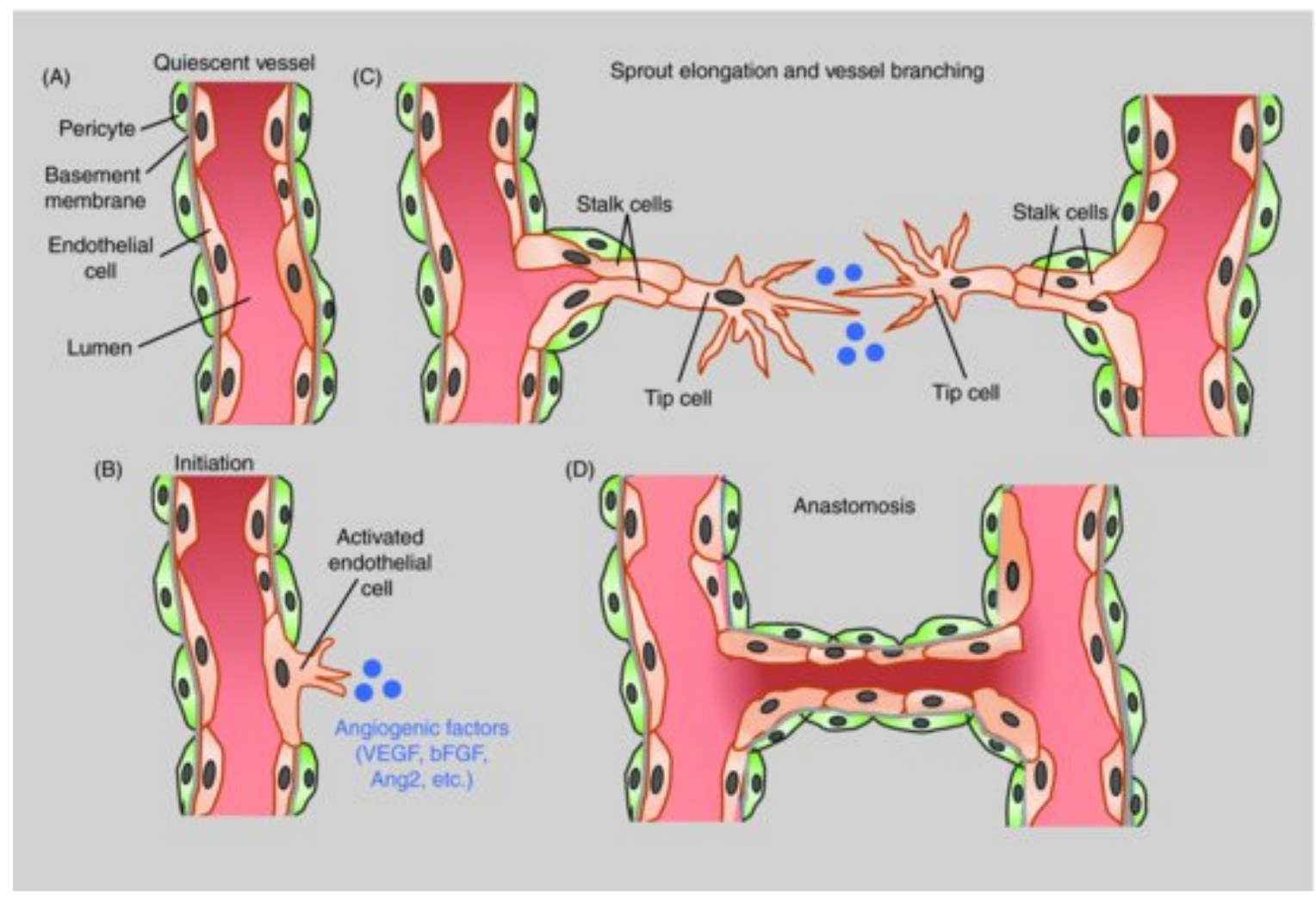

Figure 1.1. Angiogenesis process. Undernourished tumour tissue secretes angiogenic factors which signal the initially quiescent vessel to start proliferating. Endothelial cells that line the vessel wall differentiate into tip and stalk cells and subsequently follow the increasing growth factor gradients. As the newly formed vessels proliferate towards the tumour, they can branch, fuse together (anastomise) or regress. [5]

Cancer cell metastasis is a highly complex process which is widely studied up to this day. Although we are learning much about specific cell-cell and cell-ECM interactions, certain steps in the process are nonetheless well established. In order for cancer cells to metastasize 
to other body parts, they must first break from the local tumour tissue. Once detached, they must penetrate the vasculature and survive in the circulation. Moreover, they must overcome the immune response and extravasate from the vasculature to enter other tissues [6]. Naturally, should blood vessels penetrate the tumour tissue itself, intravasation into circulation is more likely to occur.

Standard in vitro methods for studying cell migration and angiogenesis include tube formation assays [7], chemotaxis (Boyden chamber) assays [8], and hanging drop assays [9], to name a few. Each platform offers different benefits for different applications. For instance, tube formation assays involve culturing cells on a gel substrate and observing the formation of tubule networks, and are suitable for drug screening applications due to its scalability and arrayable format. Boyden chamber (and similar Transwell) assays are useful for studying chemotactic cell migration due to the simplicity of its experimental setup and the ease of cell counting for quantification. Hanging drop assays involve incorporating endothelial cells into multicellular spheroids formed by traditional hanging drops, which enables formation of tubular networks and luminal structures for modelling tumour-EC interactions. Besides in vitro assays, numerous in vivo assays have also been developed for studying angiogenesis, including mouse cornea micropocket assays [10] and dorsal chamber assays [4]. Detailed reviews of in vitro and in vivo angiogenesis assays are available for the interested reader $[11,12]$.

Recently, microfluidics has become a useful platform for studying cell migration, angiogenesis, and other cancer-associated cellular phenomena, particularly within microscale environments with improved spatiotemporal control and physiological relevance. Besides the conventional in vitro methods, Kim and $\mathrm{Wu}$ [13] categorized microfluidic devices for cell 
migration studies into four broad categories, namely: (i) convection flow-based devices [14], (ii) diffusion-based devices [15], (iii) hybrid convective-diffusive devices [16], and (iv) hydrogel-based devices [17]. In convective flow-based microfluidic devices, fluid flow with different chemical concentrations are introduced directly into the microchannel, which establishes a chemical gradient for chemotactic cell migration. Diffusion-based devices have source and sink microchannels that are used to establish the chemical gradient by diffusion, allowing cells to sense the chemical gradient without direct exposure to the flow. In hybrid convective-diffusive devices, sink and source microchannels are separated by microcapillaries, which allow efficient diffusion of molecules while also preventing cells found in the middle chamber to sense the flow. Hydrogel-based devices typically consist of three parallel microchannels, including source and sink channels on the sides with the hydrogel-filled microchannel in the middle [17]. Our lab has developed hydrogel-based devices [18], where sink and source microchannels are connected via interconnecting migration channels or "migration ports" that are filled with hydrogel to allow chemical gradients to be established. In one configuration, the source channel is loaded with a high concentration of VEGF, while the sink channel is seeded with endothelial cells and fed with culture media without VEGF. Besides allowing a gradient to form, the hydrogel also serves as a 3D scaffold for 3D migration of ECs, which is representative of the extracellular matrix (ECM) found in vivo.

It is evident that microfluidic systems are becoming increasingly useful as experimental tools, with various research groups developing microfluidic systems to study angiogenic sprouting [18-20], endothelium migration [21,22], and applications in drug development [23]. However, challenges remain in several aspects of designing and using microfluidic 
systems, namely: (1) device design and operation rely heavily on trial-and-error methods with limited systematic optimization; and (2) the effects of microenvironmental factors on migration and angiogenesis processes are mostly empirical with limited theoretical basis. Mathematical and computational modelling of cell migration and angiogenesis have been performed previously for various in vitro and in vivo assays to provide additional insights and offer a theoretical basis for cellular processes. Integrating mathematical and computational modelling with microfluidic-based assays has potential to enable greater control over experimental parameters, provide new insights into fundamental angiogenesis processes, and assist in accelerating design and optimization of operating conditions. The purpose of this thesis was to apply mathematical and computational modelling of cell migration and angiogenesis specifically to microfluidic cell culture systems, with the goal of establishing an approach that would serve as a guide to designing and optimizing microfluidic devices and cell culture protocols.

In Chapter 2, a literature review is provided on current mathematical models of cell migration and angiogenesis. Namely, three major types of approaches are discussed: continuum, discrete and hybrid models. In Chapter 3, several initial models chosen for investigation are discussed in the context of their appropriateness and feasibility for application with microfluidic systems. In Chapter 4, we present two continuum models that were adopted in our analysis. In the chapter we present methodology, EC migration and angiogenesis simulations, model validation against experimental data and application to microfluidic device design optimization for the purpose of enhancing angiogenesis. Lastly, in Chapter 5 we present conclusions and potential ways of extending the models in future work. 


\section{Chapter 2}

\section{Background and Literature Review - Mathematical Modelling of Cell Migration and Angiogenesis}

In this chapter, we review the literature on the three general types of mathematical models of

angiogenesis: (i) continuum, (ii) discrete and (iii) hybrid models. A comprehensive review of these models is presented in [24]. Most of continuum models are derived from the mass conservation law and use coupled Partial Differential Equations (PDEs) to provide average description of variables. Although discrete and hybrid models provide qualitative description of vessel network morphology, they are theoretically more complex and computationally more intensive. Since our aim was to develop a computational framework that would assist researchers pursuing cell culture experiments with the design of microfluidic devices, average description of cell and vessel densities as well as VEGF concentration was deemed sufficient to model chemotactic cell migration and angiogenesis. Hence, this thesis primarily utilizes continuum approaches, but all three types of methodologies will be reviewed.

\subsection{Continuum Models}

In 1976, Deakin et al. [25] proposed a model which consisted of two convection-diffusion equations and captured tip endothelial cell (TEC) migration under general tumour angiogenic factor (TAF) which was assumed to be secreted by the tumour. Numerous later continuum models adopt a similar approach and add additional levels of complexity to make the model more physiologically relevant.

The next important step in continuum modelling was differentiation between stalk (vessels) and leading TECs. This distinguishing feature was incorporated by Balding and McElwain in 1985 
[26]. They extended the mathematical framework proposed by Edelstein et al. [27] since it modelled the growth and branching of fungal morphologies and could therefore be applied to angiogenesis and capture its processes such as branching and anastomosis. Balding and McElwain's work can be viewed as a corner stone due to the assumption that vessel creation takes place because of TEC migration; a method referred to as 'snail-trail-approach'. The name 'snail-trail' refers to the fact that the TEC migration creates behind itself a continuous blood vessel and acts as the primary mechanism responsible for creation of blood vessels.

Chaplain and Stuart [28] casted the model onto a finite one-dimensional domain and accounted for TAF consumption by ECs. Their model did not differentiate between blood vessels and leading TECs. It consisted of only two variables: endothelial cell density and TAF concentration. On the other hand, Byrne and Chaplain in 1995 [29] differentiated between the vessel and TEC density, and further extended Balding and McElwain's model to capture secondary TEC creation (Fig. 2.1).

In order to provide insight into blood vessel recruitment process, Byrne and Chaplain investigated parameters that dictate success of tumour neovascularization. Their model consisted of three independent variables: n-tip cells per unit area in the cross-sectional plane perpendicular to the front propagation, $\rho-$ vessel density length per unit cross-sectional area, and a-TAF concentration, measured in mean concentration per unit of cross-sectional area. Their numerical simulations confirm the phenomena discovered by Muthukkaruppan et al. [30] where the vessel density is higher behind the leading TECs - referred to as 'brush-border' effect. Furthermore, the aim of their work was to study the balance between chemotaxis and cell death, which has strong impact on the outcome of tumour neovascularization and therefore ability to provide useful information regarding the measurable quantities that can be experimentally tested. 
Orme and Chaplain [31] focused on the role of haptotaxis (Fig. 2.1). Besides migrating in response to an increasing TAF gradient, TECs also migrate in response to an increasing fibronectin concentration in the extracellular matrix (ECM). In addition, the authors investigated anti-angiogenesis strategies through parameter variation. Anderson and Chaplain [32] extended the Orme and Chaplain's model to two dimensions.

Continuum models kept evolving and in 2000, Levine et al. [33] studied the role of chemotaxis, haptotaxis, ECM degradation, and angiogenesis inhibition with a rather complex mathematical model which required 60 parameters to be calibrated. Plank et al. [34] extended continuum approaches to account for random walk of TECs. Holmes and Sleeman [35] studied mechanochemical interaction between cells and the ECM.

Another branch of models which focuses primarily on modelling chemotaxis is particularly relevant to this thesis. Costanzo et al. [36] developed a continuum model to study endothelial cell migration in Boyden Chamber. Serini et al. [37] utilized a model proposed in [38] to model formation of vascular patterns under the influence of a chemoattractant (Fig. 2.1). Cell density is coupled to diffusion of VEGF through the differential equation which describes the cell velocity and views increasing gradients as cues for migration. 

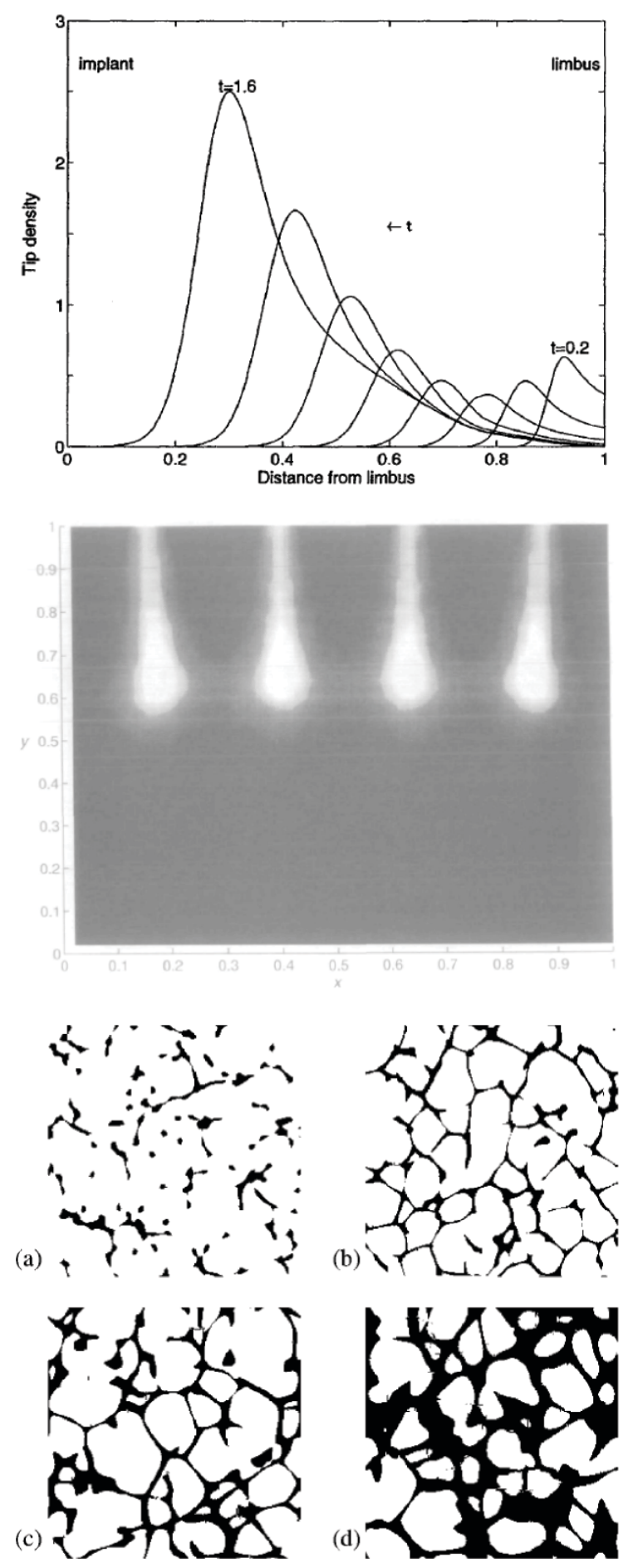

Figure 2.1. Continuum models. Cell density propagation from the right towards the tumour implant on the left [29] (Reproduced with permission from Elsevier). Endothelial cell distribution following the TAF gradient $\mathrm{c}=1-\mathrm{y}$ [31] (Reproduced with permission from Oxford University Press). Vascular network formation [38] (Reproduced with permission from American Physical Society). 
In addition, recent work performed by Connor et al. [39] utilized a continuum approach introduced by Balding \& McElwain [26], and Byrne \& Chaplain [29]. Integration of image analysis, computational modelling and mouse cornea experiments allowed them to make hypotheses regarding the synergistic effect between VEGF and FGF. The model simulated growth of mature and immature vessel length density, sprout tip cell density migration and diffusion of VEGF and FGF inside cornea as well as the implanted nylon pellet domain. Computational results were in good agreement with experiments, proving the continuum approach useful not only in modelling angiogenesis but also in generating hypotheses that can be experimentally tested. Authors conducted a local parameter sensitivity analysis and investigated coefficient significance relative to one another. First, they defined 3 metrics which characterized the vascular density profiles and individually then tuned model parameters to observe the changes. By varying the parameters by approximately $\pm 10 \%$ from the values used in their model, which were selected based on literature values that were experimentally determined, they could compare the changes in the metrics. They concluded that the most significant parameters which influenced the availability of VEGF were the distance between the limbal vessels and the VEGF source, diffusion coefficient and decay coefficient of VEGF. In terms of coefficients that characterized the EC response to VEGF, were the chemotactic coefficient, together with coefficients which quantified the sprouting of new vessels and the amount of vessels left behind. Finally, they concluded that the most significant parameter is the distance between the limbal vessel and the VEGF source, which was twice as influential than any other parameter. They used coefficient values reported in literature whenever possible and manually tuned the parameters whenever necessary, while ensuring that they are physically realistic. In fact, we also adopt this approach to parameter tuning in our methodology. These mathematical models have proven to be 
powerful tools to help understand angiogenesis that happens in mouse eye experiments, but these have yet to be applied to microfluidic systems.

In this thesis we pursue the simpler continuum approach of Gamba's [38] together with Connor's model [39], as we are interested in average response of cells to VEGF gradients inside our microfluidic device and agreement between the two models. We refer to them as cell and vessel models, respectively.

\subsection{Discrete Models}

The first probabilistic model of angiogenesis was developed by Stokes and Lauffenburger in 1991 [40]. In contrast to continuum models which provide average description and are useful in determining vessel network expansion rate, Stokes and Lauffenburger's model was able to generate results regarding detailed vessel length and morphology of the vessel network (Fig. 2.2). The primary focus was on random motion and chemotaxis of TECs. The model captures fundamental processes of angiogenesis such as: cell proliferation, migration (chemotaxis and random motility), anastomosis, and budding off from the newly formed vessels. It is a twodimensional, agent-based lattice-free model which also rests upon the snail-trail assumption (TEC movement creates/leaves vessels behind). Stochastic ordinary differential equation (ODE) is utilized to describe 2D velocity of the TECs. Cells are exposed to a steady-state profile of acidic Fibroblast Growth Factor (aFGF) which is released by a source (tumour) at the opposite end of the domain and ultimately governs cell migration. The model parameters, such as chemotactic coefficient, are determined from the in vitro experiments (Stokes et al.[41]). Their results were consistent with in vivo assays which lead to the conclusion that the TEC migration is crucial in determining the growth of vessel network. 
Plank and Sleeeman [34] build on the work of Hill and Häder [42] and develop a discrete, biased random walk model of angiogenesis to assess the inhibitor role of angiostatin. Similarly, in 2008 Milde et al. [43] develop a detailed 3D discrete model which captured the effects of soluble growth factors as well as the matrix-bound growth factors found in the ECM. Breakthrough in discrete modelling happened in 2009 when Bentley et al. [44] proposed a hierarchical agentbased model which accounted for DII-4 lateral inhibition, responsible for tip and stalk cell differentiation. The model was successful at reproducing the observed experimental pattern where tip cells are differentiated from stalk cells at the start of angiogenesis (Fig. 2.2). This phenomena is sometimes referred to as a 'salt and pepper pattern' formation. Moreover, special models are the so called Cellular Potts models, initially proposed by Glazier and Granner in 1991 [45]. They assume that cells occupy certain lattice sites and are assigned bond and spin energies through the Hamiltonian energy function. The methodology was later developed by Bauer et al. in 2007 [46] to include random motion, chemotaxis, haptotaxis and interaction with the ECM.

An innovative approach was proposed by Anderson and Chaplain in 1998 [32] where they developed a discrete Cellular Automata model by discretizing nonlinear PDEs to simulate migration of TECs. The model captures random motility of cells, chemotaxis and interaction with extracellular matrix (ECM) through incorporating fibronectin macromolecule. In addition, the model allowed for anastomosis, mitosis and branching to be included. Once the PDEs were discretized it became possible to solve for probabilities, determined by chemotactic and haptotactic stimuli, which governed movement of TECs. This model was later extended to three dimensions by Chaplain et al. [47] and accounted for blood flow in the model of McDougall et al. [48]. Their findings were in good qualitative agreement with in vivo experiments for rabbit and mouse eye cornea angiogenesis assays. 
In 2001 Tong et al. [49] developed a model of angiogenesis for the cornea pocket assay geometry. Their model captured well-established processes such as: random motility, chemotaxis, anastomosis, growth from existing vessels but also cellular uptake and chemical inactivation of angiogenic factors in ECM. This was the first model to impose a circular structure of limbus vessels as the initial condition and a source of angiogenic factors inside rectangular Cartesian coordinates. The model was later extended by Harington et al. [50] where they, besides source of TAF, such as basic Fibroblast Growth Factor (aFGF), also incorporate an inhibitor source, such as thrombospondin-1 (TSP). As expected, results showed that vascular growth is deterred in the domain where inhibitor is present. In addition, Tong et al. [51] improved the model by modelling diffusion of bFGF more accurately.

Mathematical modelling of angiogenesis is highly desirable to provide a theoretical basis for advancing angiogenesis microfluidic systems. Das et al. [52] recently showed that discrete modelling can reproduce morphology that is observed in angiogenesis microfluidic assays and is very useful in understanding the fundamental processes of angiogenesis (Fig. 2.2). 

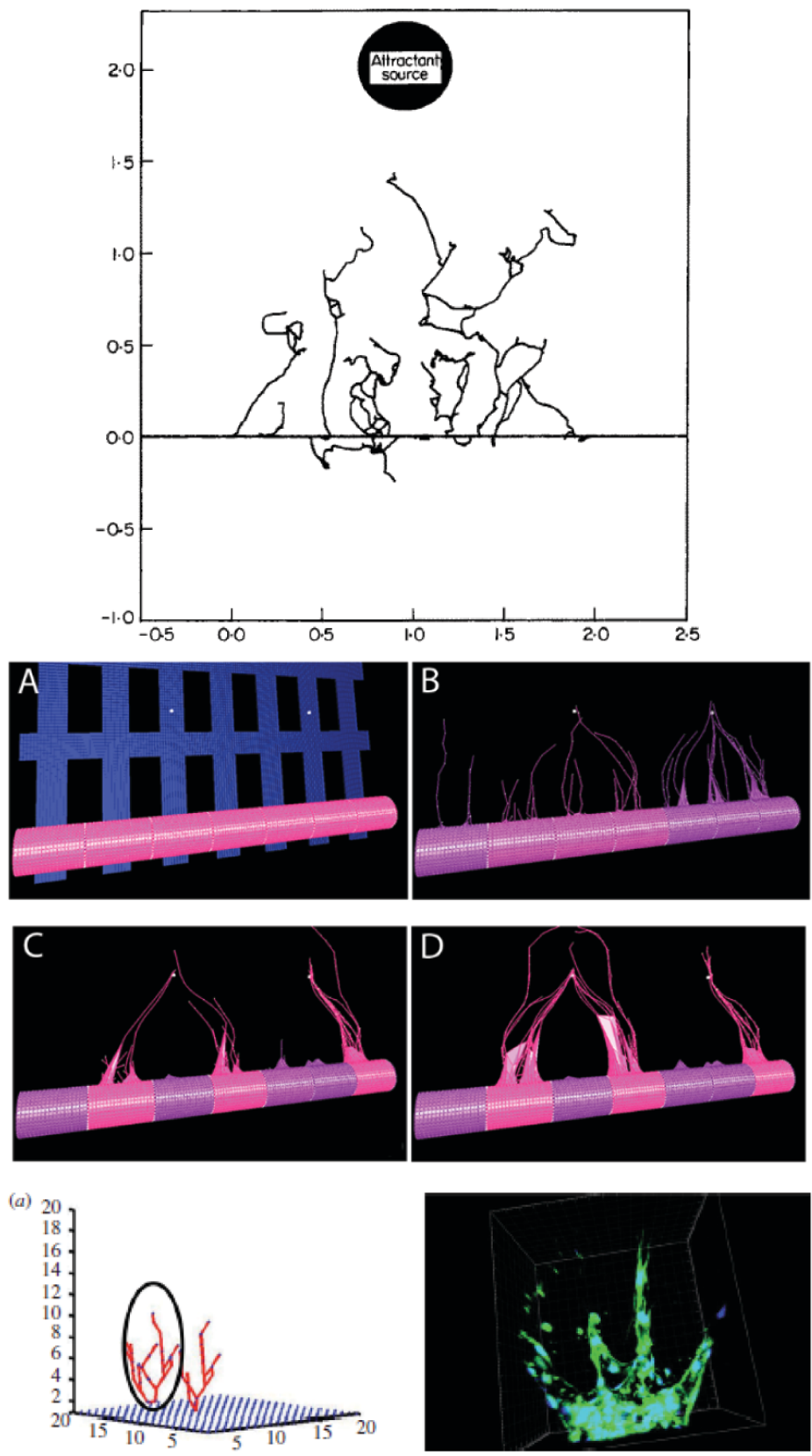

Figure 2.2. Discrete models. Angiogenesis with moderate chemotactic response under attractant source [40] (Reproduced with permission from Elsevier). Angiogenesis simulations illustrating initial tip/stalk pattern selection [44] (Reproduced with permission from PLOS Computational Biology). Simulations and experimental angiogenesis results [52] (Reproduced with permission from The Royal Society). 


\subsection{Hybrid Models}

One disadvantage to discrete modelling is that they become computationally intensive as number of cells increase. Although most discrete models adopt the snail-trail approach, computational intensity is still very high. Benefit of the hybrid models is that they can take advantage of continuum model's computational effectiveness and produce relevant vessel network morphologies through the phase-field approach. One such model is proposed by Travasso et al. [53] where TECs are treated as discrete entities while the rest of the variables are modelled through the continuum approach (vessel density and TAF concentration). The model was further improved by Vilanova et al. [54] where they utilize computationally effective isogeometric analysis to model angiogenesis and study the importance of vascular regression and regrowth (Fig. 2.3). Although discrete and hybrid models provide qualitative description of vessel network morphology, they are theoretically complex and computationally intensive. Since the needs of our lab are centered around utilizing mathematical modelling as a microfluidic device design tool, average description of cell density that would be able to predict the migration distance under various growth factor concentrations was deemed as sufficient which led us to pursue continuum models 

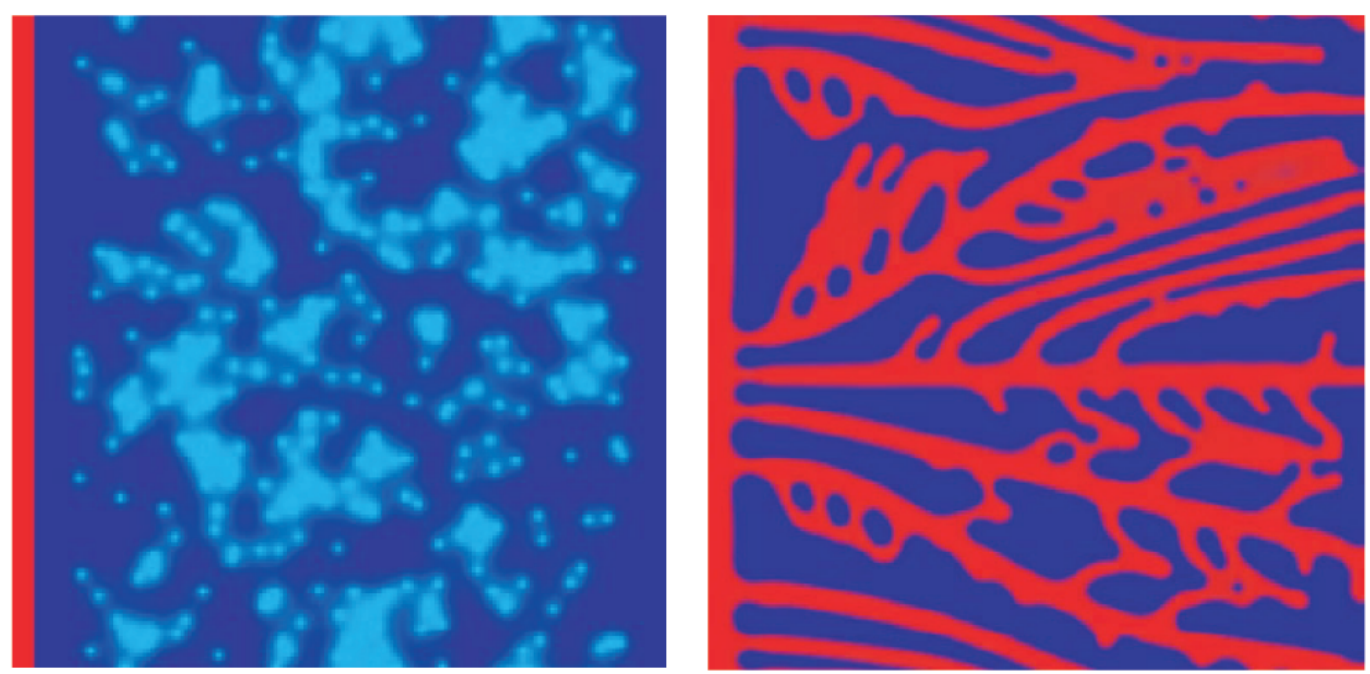

(a)

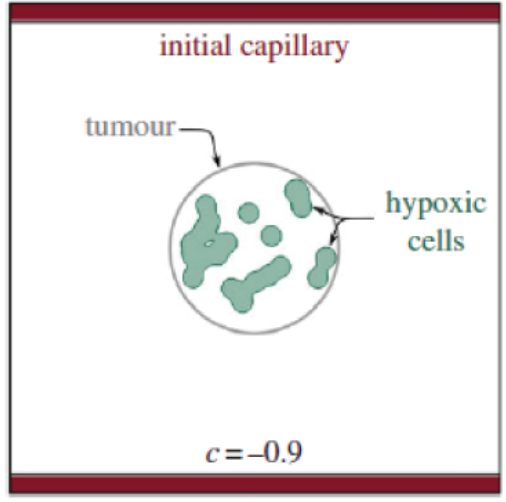

(b)

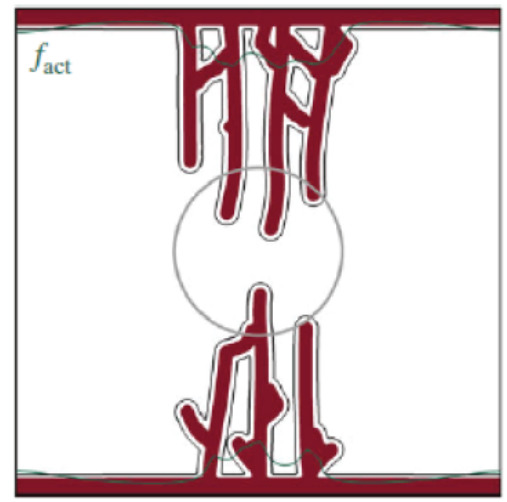

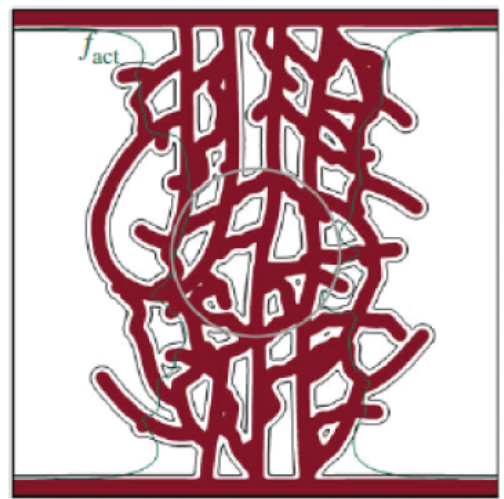

Figure 2.3. Hybrid models. Growth of capillary network [53] (Reproduced with permission from PLOS One). Tumour induced angiogenesis [54] (Reproduced with permission from The Royal Society). 


\subsection{Thesis Objectives}

These reports have demonstrated how mathematical models can be powerful tools for advancing our understanding of angiogenesis, specifically in mouse cornea experiments. To date, however, these mathematical models have not yet been integrated with microfluidic systems. Applying mathematical models to microfluidic systems has potential to enable researchers and microfluidics engineers to better design and operate their microsystems, and offer new insights based on hypotheses generated from highly controlled in vitro experiments.

Objective of this thesis was to develop and apply a combined mathematical and computational modelling framework and specifically tailor it for microfluidic cell migration and angiogenesis systems. The goal was to allow optimization of the engineering design of microfluidic systems, where the model may be used to test the impact of various geometric parameters on cell migration and angiogenesis processes, and assist in identifying optimal device dimensions to achieve desired readouts. With this goal in mind, we pursued the following two specific aims:

1. Explore the implementation of 3 independent computational modelling approaches to assess their feasibility for application to microfluidic systems, and select one of the approaches for further analysis.

2. Using the chosen modelling approach, extend the mathematical model to cell migration and angiogenesis with microfluidic geometries, and establish for use as a guide for microfluidic design and geometry optimization.

We chose to employ a continuum mathematical models based on the work of Gamba et al. [38] and Connor et al. [39] and focused on examining the average response of cells to VEGF 
gradients inside our microfluidic device, including the time-dependent changes in cell density and vessel density, and how they are affected by changes in migration port width and length. Our work demonstrates how mathematical modelling may be integrated with microfluidics to offer new perspectives on emerging problems in biomicrofluidics and cancer biology. 


\section{Chapter 3}

\section{Investigated Models}

As part of this thesis we have investigated numerous modelling approaches and will report only two models which were pursued, besides the actual 1D continuum models which are presented in Chapter 4.

\subsection{Two-dimensional (2D) Continuum Model}

The model utilized in our initial study was based on the continuum model proposed by Anderson and Chaplain [32]. The model was derived from the conservation of mass equation for ECs. The governing Equation (3.1) of EC density captures random motility, chemotaxis and haptotaxis due to VEGF and FN, respectively.

$\frac{\partial n}{\partial t}=D_{n} \nabla^{2} n-\chi_{0} \nabla \cdot(n \nabla c)-\rho_{0} \nabla \cdot(n \nabla f)$

where $n$ is number of ECs per unit area, $D_{n}$ is EC random motility coefficient, $\chi_{0}$ is chemotactic coefficient, $c$ is VEGF concentration, $\rho_{0}$ is haptotactic coefficient and $f$ is FN concentration.

The nature of the model implies migration of cells towards a positive VEGF and FN gradients. The first term on the right side, indicates random motility of ECs, while the second and third terms indicate chemotactic and haptotactic responses, respectively. Eq. (3.2) presents the model in dimensionless form.

$\frac{\partial n^{\prime}}{\partial t^{\prime}}=D^{\prime} \nabla^{2} n^{\prime}-\chi^{\prime} \nabla \cdot\left(n^{\prime} \nabla c^{\prime}\right)-\rho^{\prime} \nabla \cdot\left(n^{\prime} \nabla f^{\prime}\right)$

where

$n^{\prime}=\frac{n}{n_{0}}, \quad c^{\prime}=\frac{c}{c_{0}}, \quad f^{\prime}=\frac{f}{f_{0}}, \quad t^{\prime}=\frac{t}{\tau}, \quad x^{\prime}=\frac{x}{L}, \quad y^{\prime}=\frac{y}{L}$ 
$D^{\prime}=\frac{D_{n}}{D_{n}}, \quad \chi^{\prime}=\frac{\chi_{0} c_{0}}{D_{n}}, \quad$ and $\rho^{\prime}=\frac{\rho_{0} f_{0}}{D_{n}}$

with $n_{0}, c_{0}, f_{0}$ and $\tau$ being the characteristic variables used for non-dimensionalization. Model coefficients were obtained based on experiments performed by Stokes et al. [41].

To implement the model in FEniCS [55], the governing Eq. (3.1) had to be cast into variational form as presented in Eq. (3.3).

$\int\left\{\frac{n^{\prime}-n^{\prime n-1}}{d t^{\prime}} v+D^{\prime}\left(\nabla^{\prime} n^{\prime} \cdot \nabla^{\prime} v\right)+\chi^{\prime} \nabla^{\prime} v \cdot\left(n^{\prime} \nabla^{\prime} p^{\prime}\right)+\rho^{\prime} \nabla^{\prime} v \cdot\left(n^{\prime} \nabla^{\prime} c^{\prime}\right)\right\} d \Omega=0$

where $v$ is the test function. The system was solved using Newton solver with a time-step of $d t=0.05$ (dimensionless), on a $30 \times 30$ unit-square grid. Due to VEGF and FN diffusion coefficients being significantly larger than the EC random motility coefficient, VEGF and FN distributions were assumed to be in steady-state. A zero-flux Neumann boundary condition (BC) was applied on all four sides of the domain for the EC $(n)$ field.

Anderson and Chaplain assumed approximately circular tumour at dimensionless coordinates $\left(x^{\prime}, y^{\prime}\right)$ of $(1,0.5)$ to act as the source of VEGF. The steady-state distribution of VEGF is applied through Eqs. (3.4) - (3.5) and illustrated in Figure 3.1a.

$$
\begin{aligned}
& c(x, y, t)=\frac{(k-r)^{2}}{k-0.1} \\
& r=\sqrt{(x-1)^{2}+\left(y-\frac{1}{2}\right)^{2}}
\end{aligned}
$$

where $k$ is another parameter.

It was also of interest to investigate the influence of an increasing $\mathrm{FN}$ distribution described by Eq. (3.6) and illustrated in Fig. 3.1b. 
$f(x, y, t)=0.75 x$

In our analysis, we simplify the diffusion port geometry to a uniform square. Initial condition for EC density was assumed to resemble semicircular cell clusters (Fig. 3.1c). Chemotactic cell migration at 1.125 days is illustrated in Fig. 3.1d.

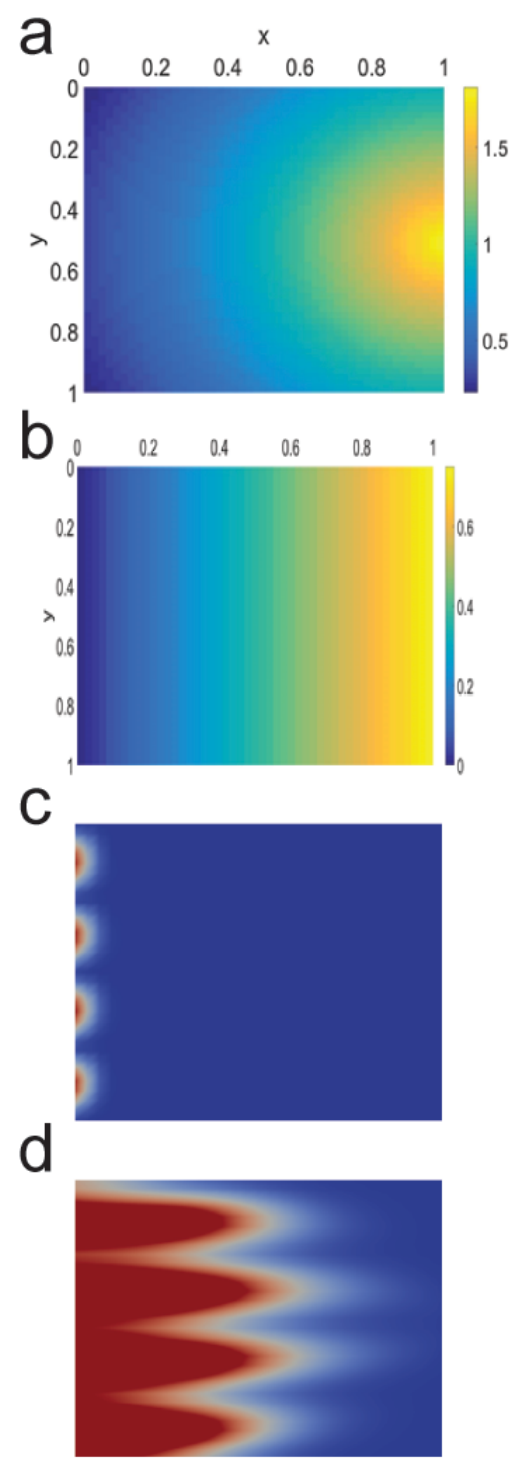

Figure 3.1 Initial development of Anderson and Chaplain's model [32]. (a) Steady-state VEGF distribution. (b) Linear steady-state FN distribution. (c) Initial EC distribution. Red indicates high and blue indicates low EC density. (d) EC migration due to VEGF and FN gradient at $\mathrm{t}=$ 1.125 days. 
As we assumed that there is a tumour at the right end which serves as a source of VEGF and the diffusion port in our microfluidic device to be coated unevenly (linearly) with FN, induced both chemotaxis and haptotaxis due to increasing VEGF and FN gradients, respectively. However, as this is a continuum model, we realized that no significant information regarding qualitative description of the morphology can be obtained and since our microfluidic channels are uniformly coated with FN, the two-dimensional model did not have much advantage over the onedimensional model.

\subsection{Three-dimensional (3D) Discrete Model}

Next, we investigated the open-source code through the so-called Microvessel Cancer, Heart and Soft Tissue Environment (CHASTE) platform [56]. Simulations are based on an off-lattice, cellcenter discrete model and are implemented according to approach presented in [39]. The framework shares many features as the spatial models of vascularized tissues proposed in [57]. The governing probabilistic model which describes EC random biased walk, influenced by space availability and VEGF gradient, is presented in Eq. (3.7).

$\operatorname{Pr}(x, y, t)=\frac{D \Delta t}{2 d_{x y}^{2}} \frac{N_{m}-N(y, t)}{N_{m}}\left\{1+\frac{\chi}{2 D}(V(y, t)-V(x, t))\right\}$

where $N$ is the number of cells, $N_{m}$ is the carrying capacity for movement, $V$ is the VEGF concentration, $D$ is the maximum random motility, and $\chi$ is the chemotactic coefficient.

To solve for the steady-state VEGF diffusion, Eq. (3.8) is solved.

$D \nabla^{2} c+\rho\left(c_{b}-c\right)+k c-\lambda c=0$ 
where $c$ is the extravascular concentration of VEGF, $D$ is an effective diffusivity, $c_{b}$ is the vascular concentration, $\rho$ is an effective vascular permeability that is nonzero and positive only on lattice sites occupied by vessels, $k$ is a cell consumption or release rate, and $\lambda$ is a positive rate of natural VEGF decay.

In our simulations, a parent vessel is placed at the left side of the diffusion port to represent cells seeded in the channel. The source of VEGF is placed at the right end and resulting steady-state diffusion is modelled according to Eq. (3.8). Summarized in Fig. 3.2 are results for a microfluidic diffusion port geometry with dimensions of $(100 \mu \mathrm{m}$ wide $\mathrm{x} 100 \mu \mathrm{m}$ tall $\mathrm{x} 320 \mu \mathrm{m}$ long). 


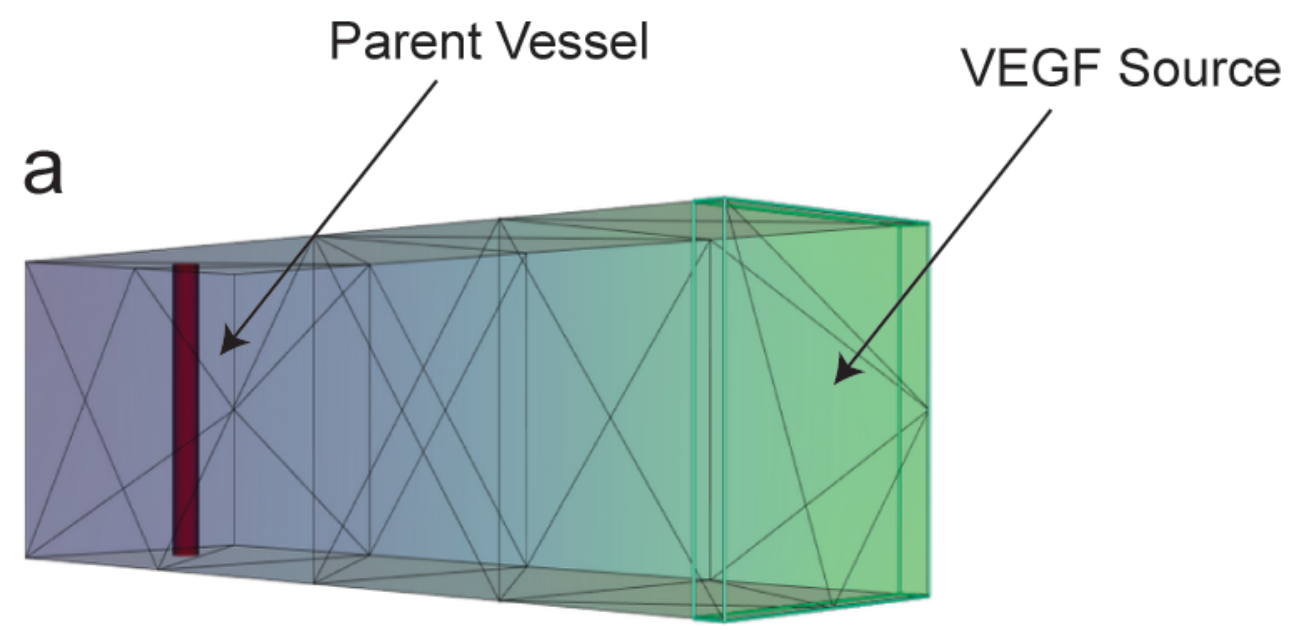

b

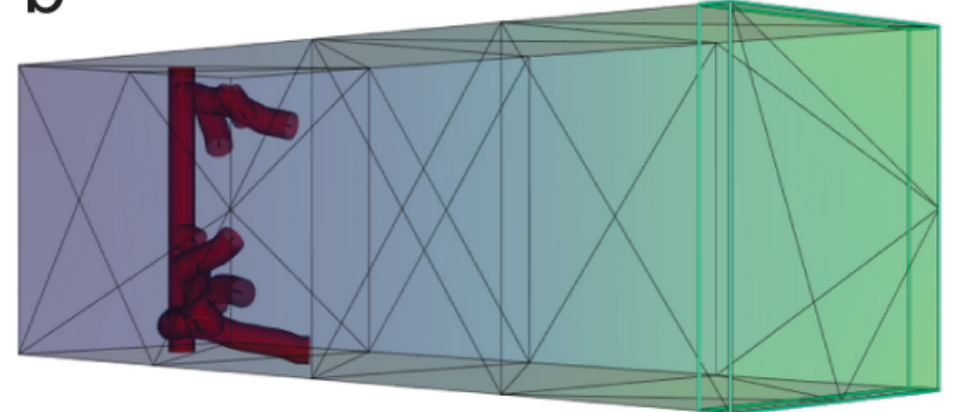

C

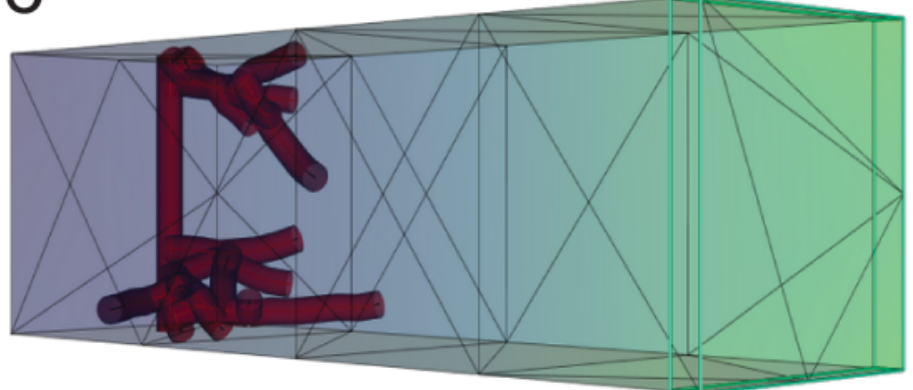

Figure 3.2 Angiogenesis simulations created by open-source software Microvessel CHASTE [56] inside the diffusion port geometry $(100 \times 100 \times 320 \mu \mathrm{m})$. (a) Initial parent vessel used to represent seeded ECs in the left channel and source of VEGF from the right channel. (b) Vessel growth at $\mathrm{t}=1$ day. (c) Vessel growth at $\mathrm{t}=2$ days.

Blood vessel growth is directed towards the increasing VEGF gradient and probability of sprouting increases with higher VEGF concentration. Results provide realistic and detailed 
vessel network morphology that would develop in vivo. However, due to complexity of the source code and lack of documentation we were unable to know with certainty what each model feature did to be able to tailor it to our microfluidic environment. For instance, the software assumed the parent vessel to be fixed and we had difficulties representing individual cells that would be lined along the lumen in the left channel. The fact that ECs in our engineered vessellike lumen structure may not behave exactly like the ECs in a typical blood vessel together with the necessity to model transient VEGF diffusion, led us to develop our own one-dimensional continuum models. 


\section{Chapter 4}

\section{Integration of Computational Modelling with Microfluidic Cell Culture Experiments}

\subsection{Rationale}

The model of Anderson and Chaplain [32] was useful in predicting chemotactic and haptotactic EC responses in 2D. However, since our microfluidic device is uniformly covered with FN (i.e., no gradient) reduced the necessity for modelling haptotaxis. Secondly, since the model is continuous, it is unable to provide qualitative description of vessel network morphology except the travel distance data. With the goal to develop models that would accurately predict EC migration and angiogenesis and could be validated against our experimental data, the model did not provide significant benefits over the 1D models and therefore we decided to pursue the latter.

Although the investigated 3D discrete model was relatively easy to adopt due to Microvessel CHASTE [56] tutorials and provide realistic qualitative description of vessel morphology, it was unfeasible to adopt in our study due to lack of flexibility in terms of tailoring it to our system. For instance, we were unable to vary the parent vessel diameter and 'tune' it to our lumen dimensions. Furthermore, it was difficult to precisely extract travel distance data of the vessel network and validate it against our experimental EC migration data. Hence, to study EC migration and angiogenesis in microfluidic environments we pursued 1D continuum approaches. 


\subsection{Theory and Methodology}

\section{Geometric Domain: The Microfluidic System}

Our group has developed microfluidic cell culture systems to study both chemotactic cell migration and angiogenic vessel growth. Our most recent system was developed to study comigration behaviour of mammary epithelial cells and neighbouring endothelial cells in a breast cancer context. Our system enabled formation of parallel double lumens (PDLs) that modelled the 3D tubular structures of both endothelial-lined blood vessels and epithelial-lined mammary ducts. The present study in mathematical and computational modelling focuses specifically on this system.

The microfluidic system consisted of two parallel microchannels (500 $\mu \mathrm{m}$ wide x $350 \mu \mathrm{m}$ tall x 7 $\mathrm{mm}$ long) connected by three connecting migration channels (i.e., "ports", $320 \mu \mathrm{m}$ wide x 100 $\mu \mathrm{m}$ tall $\times 720 \mu \mathrm{m}$ long) (Fig. 4.1a, 4.1b). Inlet and outlet reservoirs (1- and 2-mm diameters respectively, each 1-mm tall) were located at the ends of the microchannels. To form the parallel double lumens, the entire system was initially filled with a prepolymerized mixture of Matrigel (\#354230, Corning) and Type I collagen (\#354249, Corning). Lumens were created in both left and the right microchannels via a modified version of the viscous finger patterning technique. To study endothelial cell migration or angiogenic sprouting, human umbilical vein endothelial cells (HUVECs) were introduced and allowed to adhere to the inner surface of the left lumen for $24 \mathrm{~h}$. Afterwards, VEGF was introduced into the right lumen, establishing a chemical gradient across the migration ports and marking the start of the experiment $(t=0)$. For a more detailed description of the protocol please refer to [18]. 


\section{Computational Approach}

We were interested in applying two existing one-dimensional (1D) continuum models to our microfluidic geometry, one based on the work of Gamba [38] to model the density of the cell population as a continuous function, and the other based on the work of Balding \& McElwain [26], Byrne \& Chaplain [29], and Connor et al. [39] to model the density of vessels as a continuous function. Accordingly, we refer to the former as the "cell model", and the latter as the "vessel model" henceforth. To apply these two models to our system, we used an integrated computational approach, combining each continuum model with 3D numerical simulations (performed in COMSOL) to determine the biotransport of VEGF throughout the microfluidic system. Specifically, we utilized the Transport of Diluted Species COMSOL module to simulate VEGF diffusion (Fig. 4.1c). Because the microfluidic system consisted of three identical migration ports, we assumed that identical cell behaviour would occur in each migration port due to symmetry, and thus focused on only the middle migration port as our region of interest. After simulating VEGF diffusion over time, we extracted VEGF concentration values at the point in the 3D domain corresponding to the right boundary in our 1D domain (red point in Fig. 4.1d, $x^{\prime}=1$ in Fig. 4.1f). VEGF concentration values in 15-min intervals were captured (Fig. 4.1e) and imposed as a time-dependent Dirichlet boundary condition (BC) at $x^{\prime}=1$ in both the cell and vessel models. All equations in both models have been solved using the semi-analytic Method-of-Lines [58] technique. The spatial derivatives have been discretized using the finite difference method, with 150 nodes, and the system was solved using the MATLAB's ode $15 \mathrm{~s}$

routine. The advantages of Method-of-Lines are the computational efficiency, numerical stability and the well-developed state of the art solvers, such as ode $15 \mathrm{~s}$. 

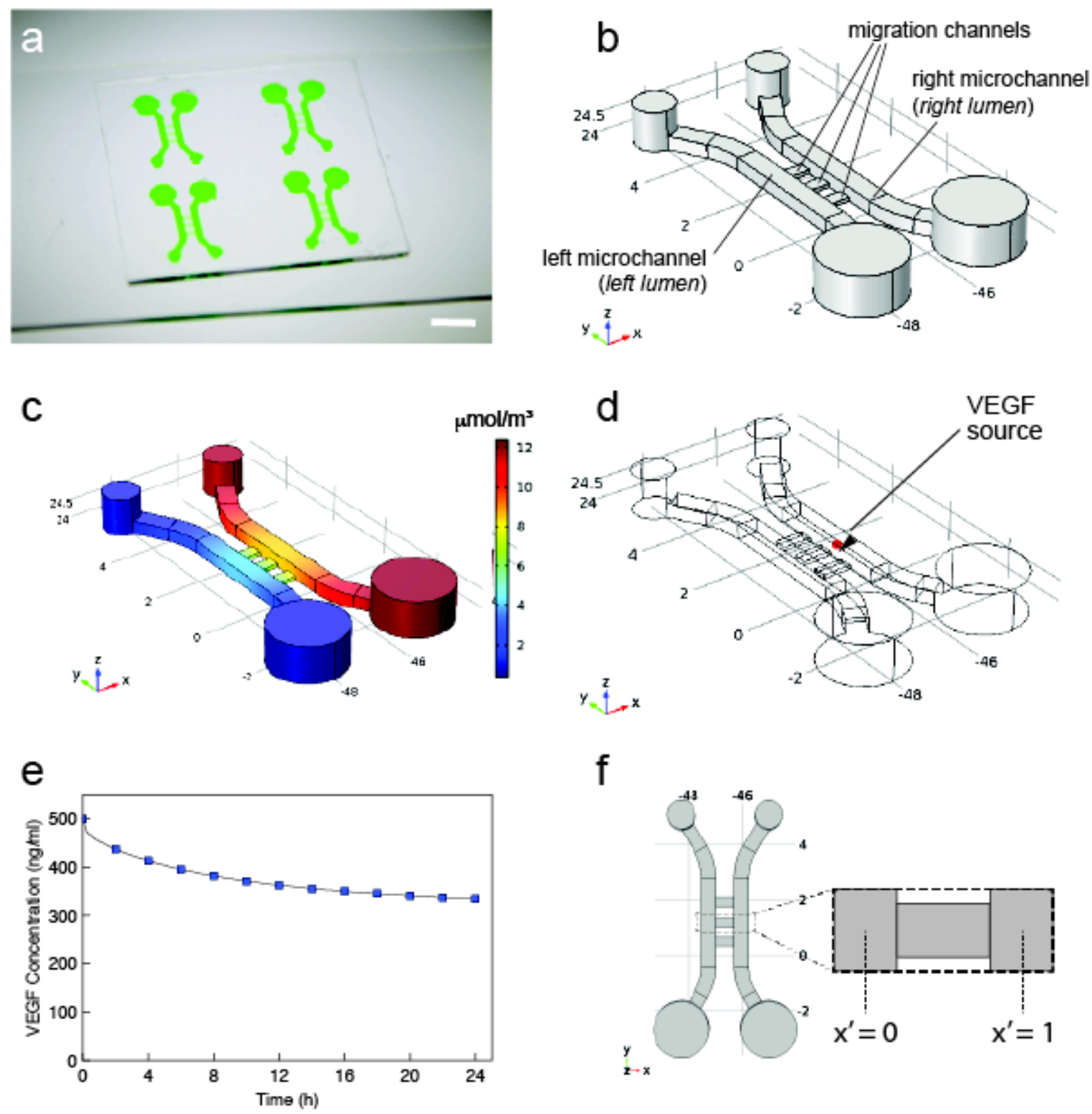

Figure 4.1. Microfluidic device geometry, nomenclature, and general methodology. (a) Image of microfluidic device used to study cancer cell migration and angiogenesis (scale bar $\sim 5 \mathrm{~mm}$ ). Device consists of $2 \times 2$ array of microfluidic cell culture systems. (b) Geometry of single microfluidic cell culture system, consisting of left and right microchannels and interconnecting migration channels. This geometry was employed for our 3D COMSOL simulations. (c) Plot of VEGF concentration in 3D microfluidic system after $24 \mathrm{~h}$ of diffusion from VEGF source. (d) Outline of microfluidic system showing location $\left(x^{\prime}=1\right.$; red point) where VEGF concentration is exported every $15 \mathrm{~min}$ and imposed as time-dependent Dirichlet boundary condition in our 1D mathematical models. (e) VEGF concentration at $x^{\prime}=1$ over $24 \mathrm{~h}$. (f) Top view projection of 3D domain. Inset illustrates the domain of interest for our 1D mathematical models ( $\mathrm{x}$ '-axis is horizontal direction). 


\section{Cell Model}

The chemotactic migration model developed by Gamba et al. [38], which we refer to here as the cell model, is governed by the following set of partial differential equations (PDEs):

$$
\begin{gathered}
\frac{\partial n}{\partial t}+\frac{\partial}{\partial x} \cdot(n u)=0 \\
\frac{\partial u}{\partial t}+u \cdot \frac{\partial u}{\partial x}=\chi \frac{\partial c}{\partial x} \\
\frac{\partial c}{\partial t}=D \nabla^{2} c-\lambda c
\end{gathered}
$$

where $n$ is endothelial cell (EC) density, $u$ is velocity (a scalar here because our model is onedimensional), $c$ is VEGF concentration, $\chi$ is chemotactic coefficient, and $D$ and $\lambda$ are diffusion and inverse degradation coefficients of VEGF, respectively. Neumann BC (zero flux) was imposed on Eq. (4.1) for EC density $n$ and zero-velocity (u) on Eq. (4.2) at the left and right boundaries. For VEGF concentration $c$ in Eq. (4.3), a zero-value Dirichlet BC was imposed at the left boundary, and a time-dependent Dirichlet BC $c=c g_{1}(t)$ was imposed at the right boundary, based on concentration values extracted from our time-dependent 3D COMSOL simulations (as described above, Fig. 4.1). Thus, the BCs are:

$$
\begin{aligned}
& x=0: \quad \nabla \cdot(n u)=0, \quad u=0, \quad c=0 \\
& x=L: \quad \nabla \cdot(n u)=0, \quad u=0, \quad c=c g_{1}(t)
\end{aligned}
$$

To model the initial condition (IC) of our experimental setup, we used a piecewise continuous function as follows:

$$
n=\left\{\begin{aligned}
1, & 0 \leq x \leq \xi \\
n_{0} \exp \left(-\frac{x^{2}}{2 \sigma^{2}}\right), & \xi \leq x \leq L
\end{aligned}\right.
$$


where $\xi$ represents the edge of the lumen. Essentially, our IC consisted of first applying a step function from the lumen centerline $(x=0)$ to the edge of the lumen $\xi$, and then smoothing out minor cell spread with a normal distribution function from $\xi \leq x \leq L$. We note that validation of our numerical results with our experimental data led us to hypothesize that different percentages of cells are activated under different VEGF concentrations. Thus, we investigated three different VEGF concentrations of 30,100 and $500 \mathrm{ng} / \mathrm{mL}$, where normalized values of $0.2,0.8$ and 1 were imposed as EC density (cell model) and vessel density (vessel model) step functions, respectively. For convenience, we non-dimensionalized Eqs. (4.1) - (4.5), resulting in:

$\frac{\partial n^{\prime}}{\partial t^{\prime}}+u^{\prime} \frac{\partial n^{\prime}}{\partial x^{\prime}}+n^{\prime} \frac{\partial u^{\prime}}{\partial x^{\prime}}=0$

$\frac{\partial u^{\prime}}{\partial t^{\prime}}+u^{\prime} \frac{\partial u^{\prime}}{\partial x^{\prime}}=\chi^{\prime} \frac{\partial c^{\prime}}{\partial x^{\prime}}$

$\frac{\partial c^{\prime}}{\partial t^{\prime}}=\mathrm{D}^{\prime} \frac{\partial^{2} c^{\prime}}{\partial x^{\prime 2}}-\lambda^{\prime} c^{\prime}$

$x^{\prime}=0$ :

$\nabla^{\prime} \cdot\left(n^{\prime} u^{\prime}\right)=0, \quad u^{\prime}=0, \quad c^{\prime}=0$

$x^{\prime}=1$ :

$$
\nabla^{\prime} \cdot\left(n^{\prime} u^{\prime}\right)=0, \quad u^{\prime}=0, \quad c^{\prime}=c g^{\prime}{ }_{1}(t)
$$

where the dimensionless quantities are defined as:

$$
\begin{gathered}
n^{\prime}=\frac{n}{n_{0}}, \quad u^{\prime}=\frac{u}{U_{0}}, \\
c^{\prime}=\frac{c}{c_{0}}, \quad c g^{\prime}{ }_{1}=\frac{c g_{1}}{c_{0}}, \quad t^{\prime}=\frac{t}{\tau}, \quad x^{\prime}=\frac{x}{L^{*}} \\
\chi^{\prime}=\frac{\chi c_{0}}{D}, \quad D^{\prime}=\frac{D}{D}, \quad \lambda^{\prime}=\lambda \tau
\end{gathered}
$$

Please note that the characteristic variables used for non-dimensionalization of the cell model have been summarized in Table 3 . 


\section{Vessel Model}

The vessel model developed by Connor et al. [39] was used here to simulate the average migration of sprout tip density $n$ and the average growth vessel length density $\rho$ in response to the average VEGF concentration $v$. The model was derived based on the mass conservation principle:

$$
\frac{\partial \rho_{i}}{\partial t}=\frac{\partial J_{i}}{\partial x}+\sigma_{i}
$$

where $\rho_{i}$ is the species density, $J_{i}$ is the flux, and $\sigma_{i}$ is the net rate of production per unit volume. The model captures established angiogenic processes, including: EC random motility, chemotaxis, vessel sprouting, tip-to-vessel anastomosis, tip-to-tip anastomosis and cell death. Random motility and chemotaxis are incorporated through a flux term, while vessels are created when tips leave a control volume, a methodology known as the 'snail-trail-approach' [26].

Here, we employed a simplified model that neglects vessel maturity and the effects of fibroblast growth factor (FGF), resulting in the following set of governing equations for $n, \rho$, and $v$ :

$$
\begin{aligned}
& \frac{\partial n}{\partial t}=\frac{\partial}{\partial x} \cdot\left(\mu \frac{\partial n}{\partial x}-\chi n \frac{\partial \mathrm{v}}{\partial x}\right)+\alpha_{0}\left(\frac{v}{v+v_{0.5}}\right) \rho-\beta_{1} \rho n-2 \beta_{2} n^{2}-\gamma n\left(\frac{v_{0.5}}{v+v_{0.5}}\right) \\
& \frac{\partial \rho}{\partial t}=\kappa\left|\mu \frac{\partial n}{\partial x}-\chi n \frac{\partial \mathrm{v}}{\partial x}\right|-\gamma \rho\left(\frac{v_{0.5}}{v+v_{0.5}}\right) \\
& \frac{\partial v}{\partial t}=D \frac{\partial^{2} v}{\partial x^{2}}-\lambda v
\end{aligned}
$$

where $\mu$ is the random motility coefficient for sprout tips; $\chi$ is the chemotactic coefficient for sprout tips to VEGF; $\alpha_{0}$ is the maximum rate of VEGF-induced tip production per vessel length; 
$v_{0.5}$ is the VEGF concentration at which VEGFR-2 receptors are half occupied; $\beta_{1}$ is the rate of tip-to-vessel anastomosis per unit vessel length density per unit tip density per unit volume; $\beta_{2}$ is the rate of tip-to-tip anastomosis per unit tip density squared per unit volume; $\gamma$ is the maximum rate of EC death in low VEGF concentrations; $\kappa$ is the coefficient which quantifies the length of vessel left behind as the sprout tip leaves unit volume; D is the VEGF diffusion coefficient, and $\lambda$ is the inverse natural decay rate of VEGF.

Similar to the cell model above, zero-flux BCs were imposed for tip cell density $n$, while a zerovalue Dirichlet $\mathrm{BC}$ for VEGF concentration was imposed at the left boundary and a timedependent VEGF concentration $v=v g_{1}(t)$ was imposed at the right boundary based on COMSOL simulations. Eqs. (4.13) and (4.15) both had zero ICs. For vessel density $\rho$, BCs were not required, while its IC was the same piecewise continuous function used for the cell model. In summary, the BCs and ICs for the vessel model were:

$$
\begin{aligned}
& x=0 \text { : } \\
& \mu \frac{\partial n}{\partial x}-\chi n \frac{\partial \mathrm{v}}{\partial x}=0, \quad v=0 \\
& x=L: \\
& \mu \frac{\partial n}{\partial x}-\chi n \frac{\partial \mathrm{v}}{\partial x}=0, \quad v=v g_{1}(t) \\
& \rho=\left\{\begin{array}{rc}
1, & 0 \leq x \leq \xi \\
\rho_{0} \exp \left(-\frac{x^{2}}{2 \sigma^{2}}\right), & \xi \leq x \leq L
\end{array}\right.
\end{aligned}
$$

where $\rho_{0}$ was manually adjusted as an experimental parameter to fit the experimental data. Nondimensionalized form of Eqs. (4.13) - (4.17) is presented below: 


$$
\begin{gathered}
\frac{\partial n^{\prime}}{\partial t^{\prime}}=\frac{\partial}{\partial x^{\prime}} \cdot\left(\mu^{\prime} \frac{\partial n^{\prime}}{\partial x^{\prime}}-\chi^{\prime} n^{\prime} \frac{\partial v^{\prime}}{\partial x^{\prime}}\right)+\alpha_{0}^{\prime}\left(\frac{v^{\prime}}{v^{\prime}+v_{0.5}^{\prime}}\right) \rho^{\prime}-\beta^{\prime}{ }_{1} \rho^{\prime} n^{\prime}-2 \beta^{\prime}{ }_{2} n^{\prime 2} \\
-\gamma^{\prime} n^{\prime}\left(\frac{v_{0.5}^{\prime}}{v^{\prime}+v_{0.5}^{\prime}}\right)
\end{gathered}
$$

$\frac{\partial \rho^{\prime}}{\partial t^{\prime}}=\kappa\left|\mu^{\prime} \frac{\partial n^{\prime}}{\partial x^{\prime}}-\chi^{\prime} n^{\prime} \frac{\partial v^{\prime}}{\partial x^{\prime}}\right|-\gamma^{\prime} \rho^{\prime}\left(\frac{v_{0.5}^{\prime}}{v^{\prime}+v_{0.5}^{\prime}}\right)$

$\frac{\partial v^{\prime}}{\partial t^{\prime}}=D^{\prime} \frac{\partial^{2} v^{\prime}}{\partial x^{\prime 2}}-\lambda^{\prime} v^{\prime}$

$x^{\prime}=0$ :

$$
\mu^{\prime} \frac{\partial n^{\prime}}{\partial x^{\prime}}-\chi^{\prime} n^{\prime} \frac{\partial v^{\prime}}{\partial x^{\prime}}=0, \quad v^{\prime}=0
$$

$x^{\prime}=1$ :

$$
\mu^{\prime} \frac{\partial n^{\prime}}{\partial x^{\prime}}-\chi^{\prime} n^{\prime} \frac{\partial v^{\prime}}{\partial x^{\prime}}=0, \quad v^{\prime}=v g_{1}^{\prime}
$$

where the dimensionless quantities are defined as:

$$
\begin{gathered}
n^{\prime}=\frac{n}{n_{0}}, \quad \rho^{\prime}=\frac{\rho}{\rho_{0}}, \quad v^{\prime}=\frac{v}{v_{0}}, \quad t^{\prime}=\frac{t}{\tau}, \quad x^{\prime}=\frac{x}{L^{*}} \\
\mu^{\prime}=\frac{\mu}{D}, \quad \chi^{\prime}=\frac{\chi v_{0}}{D}, \quad D^{\prime}=\frac{D}{D} \\
\alpha_{0}^{\prime}=\frac{\alpha_{0} \tau \rho_{0}}{n_{0}}, \quad v_{0.5}^{\prime}=\frac{v_{0.5}}{v_{0}}, \quad \kappa^{\prime}=\frac{\kappa n_{0} L^{*}}{\rho_{0}}
\end{gathered}
$$

We simplified our vessel model to focus on only one growth factor (VEGF), and to consider primarily random motility, chemotaxis, sprouting from vessels, anastomosis and regression (Table 1). Endothelial cell release and consumption of VEGF was neglected due to slight difference in derivation of two models and insignificant influence on results (which was verified in our vessel model simulations). In our models, we adopted coefficient values presented by Connor for the vessel model, except for the chemotactic coefficient, which we increased to $185 \%$, and the maximum rate of VEGF-induced tip production coefficient, which we decreased 
to $10 \%$ of the values reported in literature (Table 2). Moreover, the chemotactic coefficient in the cell model was decreased to $55 \%$ of the literature value. VEGF diffusion and decay coefficients used in the cell model were the same as in the vessel model. By manually tuning the mentioned parameters in both models, numerical results were matched against the experimental data. Connor and co-workers used coefficient values from the literature wherever possible. In instances where it was not feasible, they made reasonable assumptions and approximate coefficients that provided physically realistic results. Detailed justifications for each of the coefficients can be found in supplementary material of [39] and references listed in Table 2. The characteristic variables used for non-dimensionalization of the vessel model have been summarized in Table 3.

Table 1. Model Capabilities

\begin{tabular}{lcc}
\hline \multicolumn{1}{c}{ Capability } & Cell Model & Vessel Model \\
\hline Random motility & $\checkmark$ & $\checkmark$ \\
Chemotactic migration & & $\checkmark$ \\
Sprouting from vessels & & $\checkmark$ \\
Anastomosis & & $\checkmark$ \\
Regression & & $\checkmark$ \\
\hline
\end{tabular}


Table 2. Definition of coefficients and reference values [39]

\begin{tabular}{|c|c|c|c|c|}
\hline Coefficient & Symbol & Values & Units & References \\
\hline VEGF diffusion coefficient & $D$ & $1.95 \times 10^{-7}$ & {$\left[\mathrm{~m}^{2} \mathrm{~h}^{-1}\right]$} & {$[59],[60],[61]$} \\
\hline Random motility coefficient & $\mu$ & $6 \times 10^{-11}$ & {$\left[\mathrm{~m}^{2} \mathrm{~h}^{-1}\right]$} & [29], [62], [41] \\
\hline Chemotactic coefficient & $\chi$ & 1.837 & {$\left[\mathrm{~m}^{2} \mathrm{~h}^{-1} \mathrm{M}^{-1}\right]$} & {$[26],[29],[63]$} \\
\hline $\begin{array}{l}\text { The maximum rate of VEGF- } \\
\text { induced tip production per vessel } \\
\text { length }\end{array}$ & $\alpha_{0}$ & 2600 & {$\left[\right.$ tips $\left.^{-1} \cdot(\mathrm{m} \text { of vessel })^{-1}\right]$} & {$[39]$} \\
\hline $\begin{array}{l}\text { The VEGF concentration at } \\
\text { which VEGFR-2 receptors are } \\
\text { half occupied }\end{array}$ & $c_{0.5}\left(v_{0.5}\right)$ & $6.5 \times 10^{-10}$ & {$[\mathrm{M}]=\left[\mathrm{mol} \mathrm{L}^{-1}\right]$} & {$[64],[65]$} \\
\hline $\begin{array}{l}\text { Rate of tip-to-vessel anastomosis } \\
\text { per unit vessel length density per } \\
\text { unit tip density per unit volume }\end{array}$ & $\beta_{1}$ & $1.56 \times 10^{-9}$ & $\begin{array}{l}\text { [anastomosis instances } \mathrm{h}^{-1} \mathrm{~m}^{-3} \\
\left(\mathrm{~m} \text { of vessel } \mathrm{m}^{-3}\right)^{-1}\left({ }^{-3} \text { cells } \mathrm{m}^{-3}\right)^{-1} \text { ] }\end{array}$ & [39] \\
\hline $\begin{array}{l}\text { Rate of tip-to-tip anastomosis per } \\
\text { unit tip density squared per unit } \\
\text { volume }\end{array}$ & $\beta_{2}$ & $1.03 \times 10^{-15}$ & $\begin{array}{l}\text { [anastomosis instances } \mathrm{h}^{-1} \mathrm{~m}^{-3} \\
\left(\left(\text { cells } \mathrm{m}^{-3}\right)^{-2} \text { ] }\right.\end{array}$ & {$[39]$} \\
\hline Maximal regression rate of ECs & $\gamma$ & $2.27 \times 10^{-3}$ & {$\left[\mathrm{~h}^{-1}\right]$} & {$[66]$} \\
\hline $\begin{array}{l}\text { Coefficient for vessel length left } \\
\text { behind as sprout tip leaves unit } \\
\text { volume }\end{array}$ & $\kappa$ & 3.15 & {$\left[(\mathrm{~m}\right.$ of vessel $) \cdot$ ceells $\left.^{-1} \mathrm{~m}^{-1}\right]$} & [39] \\
\hline $\begin{array}{l}\text { Inverse Natural decay constant } \\
\text { of VEGF }\end{array}$ & $\lambda$ & 0.8 & {$\left[\mathrm{~h}^{-1}\right]$} & [39], [59] \\
\hline
\end{tabular}


Table 3. Characteristic values used for non-dimensionalization of the cell and vessel models.

\begin{tabular}{|c|c|c|c|}
\hline \multicolumn{4}{|c|}{ Cell model } \\
\hline Characteristic parameter & Symbol & Values & Units \\
\hline EC density normalization factor. & $n_{0}$ & 1 & {$\left[\right.$ cells $\left.\mathrm{m}^{-3}\right]$} \\
\hline Velocity normalization factor. & $U_{0}$ & 1 & {$\left[\mathrm{~m} \mathrm{~h}^{-1}\right]$} \\
\hline VEGF normalization factor. & $c_{0}$ & $12.8 \times 10^{-9}$ & {$[\mathrm{M}]$} \\
\hline Time normalization factor. & $\tau=\frac{L^{* 2}}{D}$ & 5.5 & {$[\mathrm{~h}]$} \\
\hline $\begin{array}{l}\text { Distance between the centerlines } \\
\text { of the left and right channel. }\end{array}$ & $L^{*}$ & $1220 \times 10^{-6}$ & {$[\mathrm{~m}]$} \\
\hline \multicolumn{4}{|c|}{ Vessel model } \\
\hline Characteristic parameter & Symbol & Values & Units \\
\hline EC density normalization factor. & $n_{0}$ & $1 \times 10^{-12}$ & {$\left[\right.$ cells $\left.\mathrm{m}^{-3}\right]$} \\
\hline $\begin{array}{l}\text { Vessel density normalization } \\
\text { factor. }\end{array}$ & $\rho_{0}$ & $5.85 \times 10^{7}$ & [m of vessel $\mathrm{m}^{-3}$ ] \\
\hline VEGF normalization factor. & $v_{0}$ & $12.8 \times 10^{-9}$ & {$[\mathrm{M}]$} \\
\hline Time normalization factor. & $\tau=\frac{L^{* 2}}{D}$ & 5.5 & {$[\mathrm{~h}]$} \\
\hline $\begin{array}{l}\text { Distance between the centerlines } \\
\text { of the left and right channel. }\end{array}$ & $L^{*}$ & $1220 \times 10-6$ & {$[\mathrm{~m}]$} \\
\hline
\end{tabular}




\subsection{Results}

\section{Model Demonstration}

To study chemotactic EC migration and angiogenesis, we applied the cell and vessel models respectively to determine cell density $n$ and sprout density $\rho$ as functions of distance into the migration port, beginning with the study of $500 \mathrm{ng} / \mathrm{mL}$ initial VEGF concentration. Both models have been implemented using MATLAB's ode15s routine through the Method-of-Lines [58]. Using the cell model, we simulated cell migration, where $t=0$ represented the beginning of cell migration starting at the center of the lumen. After $24 \mathrm{~h}$, the EC density profile $n$ traveled $\sim 25 \%$ into the migration port. EC density did not exceed unity at any point since the cell model only accounted for chemotaxis (Fig. 4.2, a-c). Similarly, the vessel model predicted the vessel density profile $\rho$ traveled $\sim 25 \%$ to $\sim 50 \%$ into the migration port (Fig. 4.2, d-f). Vessel density exceeds unity in some locations because the vessel model accounted for sprouting from vessels $\left(\alpha_{0}^{v}\right)$ and displayed slight curvature at the quarter distance which reflected tip-to-vessel and tip-to-tip anastomosis $\left(\beta_{1}, \beta_{2}\right)$, as well as regression $(\gamma)$.

Because both models are applied to the same set of cell culture experiments, the initial EC density distribution in the cell model and the blood vessel density distribution in the vessel model had to be identical in form. In other words, ICs for the cell and vessel models had to have the same standard deviation $(\sigma=75 \mu \mathrm{m})$. As mentioned, chemotactic coefficients of the cell and vessel models were tuned to $55 \%$ and $185 \%$, respectively, of the values used by Connor et al. [39] to match our experimental results (discussed below). 

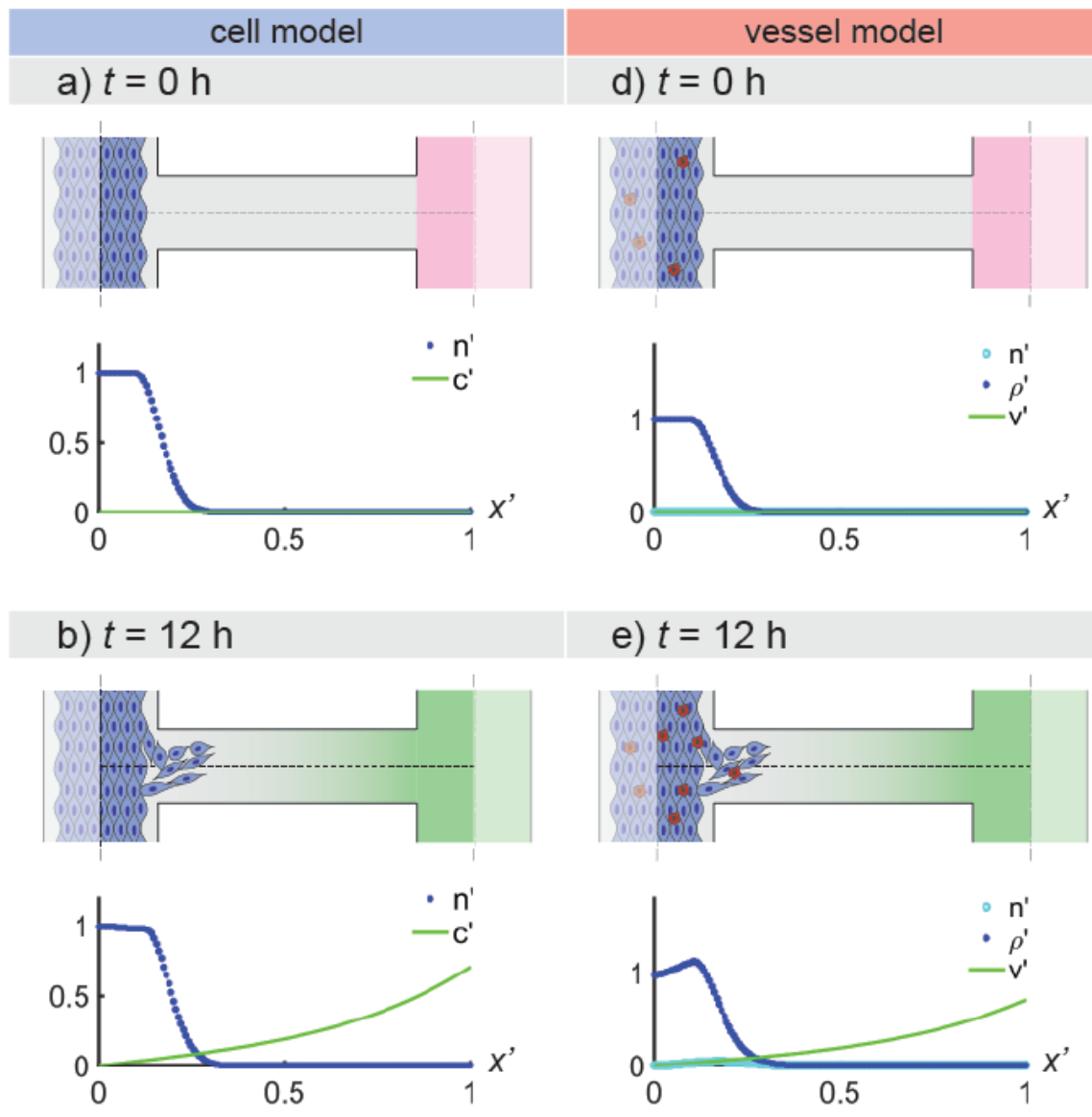

e) $t=12 \mathrm{~h}$
c) $t=24 \mathrm{~h}$
f) $t=24 \mathrm{~h}$
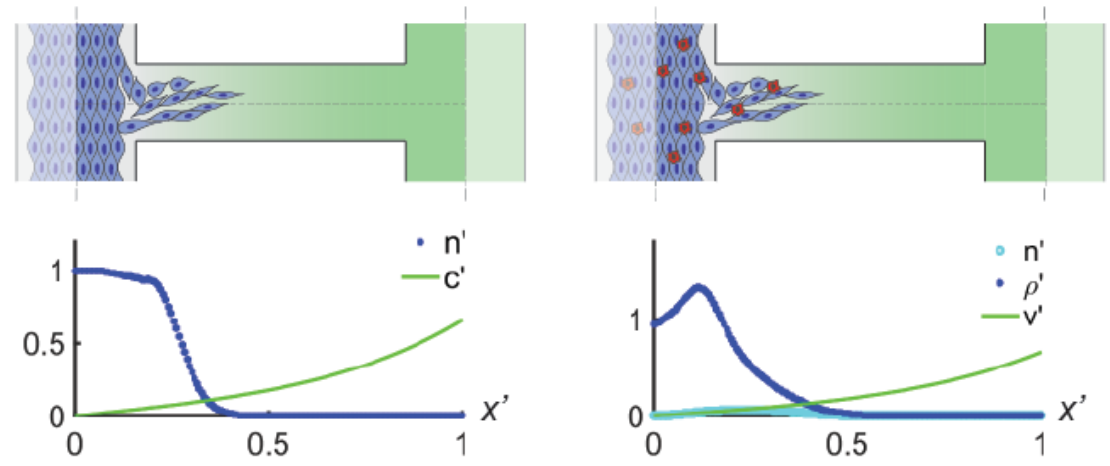

Figure 4.2. Cell migration and angiogenic sprouting as predicted using the cell and vessel models, respectively. Cell model results for (a) $t=0$, (b) $t=12 \mathrm{~h}$, and (c) $t=24 \mathrm{~h}$. Vessel model results for (d) $t=0$, (e) $t=12 \mathrm{~h}$, and (f) $t=24 \mathrm{~h}$. Illustrations are included to visually represent and help interpretation of the graphs. ECs are shown in blue, dead cells are shown in red (for d, $\mathrm{e}$, and f only). Hydrogel regions are grey, channels filled with media are pink, and the VEGF gradient is shown as green. Graphs show EC density $\left(n^{\prime}\right)$ and VEGF concentration $\left(c^{\prime}\right)$ for the cell model, and sprout tip density $\left(n^{\prime}\right)$, vessel length density $\left(\rho^{\prime}\right)$ and VEGF concentration $\left(v^{\prime}\right)$ for the vessel model, all as dimensionless quantities. Distance is represented by a dimensionless $x$ '-axis. 
Fitting Experimental Data to the Models

We used data from experiments performed in our microfluidic systems, with three different VEGF concentrations of 30,100 and $500 \mathrm{ng} / \mathrm{mL}$ over a $24 \mathrm{~h}$ period. As described previously, cells were fluorescently labeled, and images were obtained by fluorescence microscopy (EVOS FL Cell Imaging System) at $24 \mathrm{~h}$. Image analysis software (ImageJ) was utilized to determine travel distance of each individual cell. To obtain a spatial distribution of cell migration distance, we divided the horizontal axis into $10-\mu \mathrm{m}$ bins, and counted the number of cells in each bin using MATLAB. This allowed us to obtain experimental cell density "profiles" against which numerical simulations could be validated. Cell density profiles for all three VEGF concentrations were normalized against the maximum cell count (84 cells) in the $500 \mathrm{ng} / \mathrm{mL}$ VEGF experiment (thus ensuring that maximum normalized density was equal to unity). We hypothesized that different levels of VEGF concentrations resulted in different fraction of ECs being activated, leading us to impose values of $0.2,0.8$ and 1 for $n_{0}$ and $\rho_{0}$ step-functions for 30,100 and 500 ng/mL VEGF concentrations, respectively. Fig. 4.3 shows results from our comparison of the cell model (dotted lines), the vessel model (solid lines), and experimental data (filled points). Both models were in good agreement with experimental data. The reason why the vessel model had slight 'overshoots' is due to its complexity and higher level of physiological relevance. Perhaps future improvement in our lab's in vitro methods will produce experimental results that will be in better agreement with this model. 


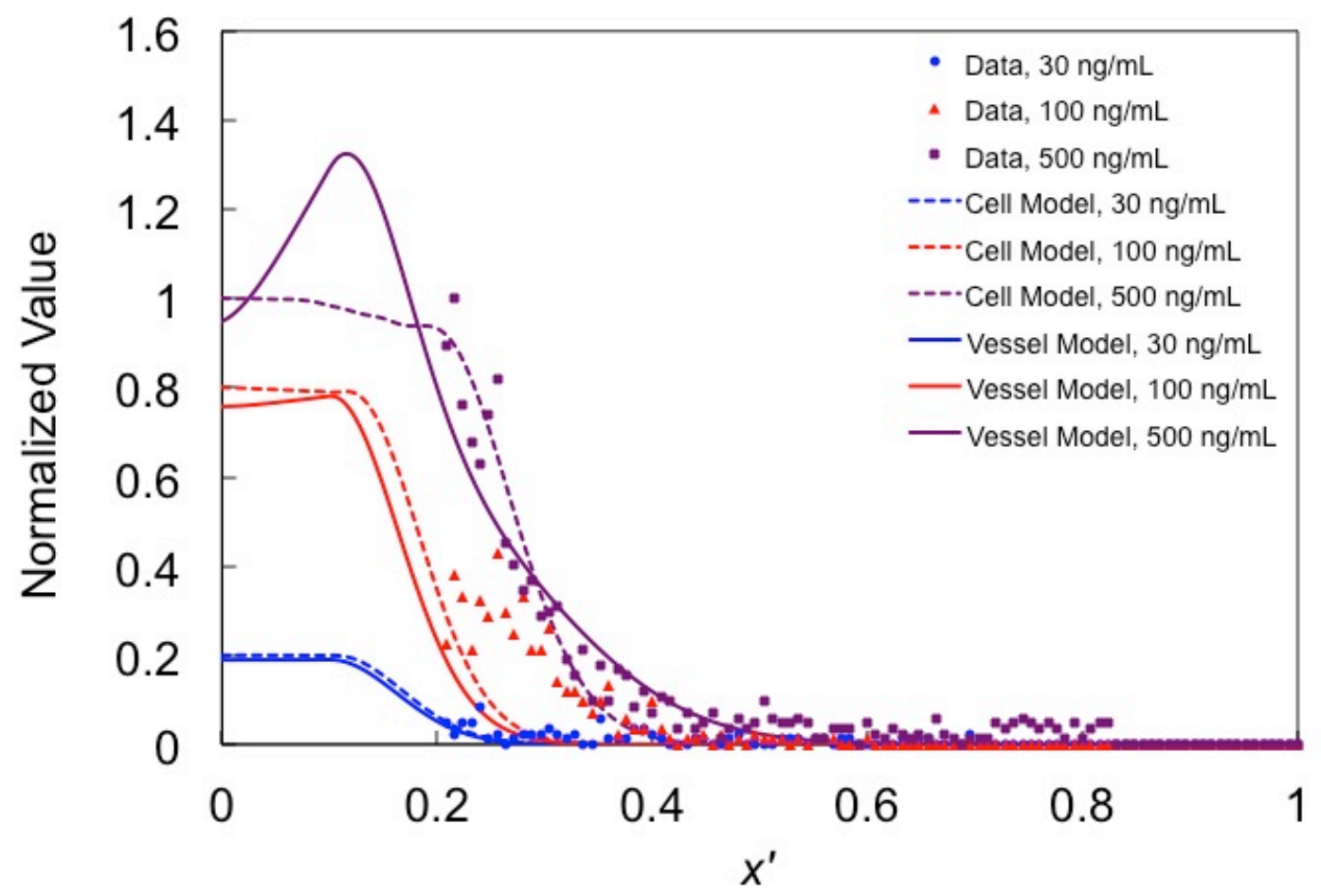

Figure 4.3. Experimental data fitted with both the cell and vessel models. (Dotted lines) EC density of the cell model; (solid lines) vessel length density of the vessel model; (filled data points) experimental data. VEGF concentrations tested included: $30 \mathrm{ng} / \mathrm{mL}$ (blue), $100 \mathrm{ng} / \mathrm{mL}$ (red), and $500 \mathrm{ng} / \mathrm{mL}$ (purple), and all results represent 24-h periods.

\section{Using the Model as a Design Tool: Geometric Changes}

We investigated the potential of geometric parameters such as migration port width and length to impact cell migration and angiogenic sprouting. Our integrated methodology (COMSOL together with the cell and vessel mathematical models) enabled us to conveniently adjust geometric parameters and test the effect of these changes on cell density and vessel density. We reasoned that such a demonstration will prove to be a useful strategy for facilitating both microsystem design and experimental design.

We focused on adjusting the dimensions of the migration ports, motivated by the idea that diffusion of growth factors such as VEGF is strongly impacted by the cross-sectional area, while 
the strength of a chemotactic response is strongly governed by the strength or "steepness" of the chemical gradient. Furthermore, the distances traveled by individual cells, or the sprout length of vessels, must be measured within a reasonable timeframe, and developing models can help predict the proper timecourse to consider for experimentation. Migration port widths were adjusted to $50 \%(160 \mu \mathrm{m})$ and $150 \%(480 \mu \mathrm{m})$ of the original width $(320 \mu \mathrm{m})$, and migration port lengths were adjusted to $75 \%(540 \mu \mathrm{m})$ and $150 \%(1.44 \mathrm{~mm})$ of the original length $(720$ $\mu \mathrm{m})$. Migration port lengths less than $75 \%$ of the original length led to ECs entering the right microchannel in our simulations, and so we chose not to discuss these cases. Representative geometries of these adjusted dimensions are illustrated in Fig. 4.4.

First, we obtained VEGF concentration curves with respect to time for each of these sets of migration port dimensions (Fig. 4.4c and f), where VEGF concentration was measured at the VEGF source location $\left(x^{\prime}=1\right)$. Increasing port width (Fig. 4.4b) led to a more rapid decrease in VEGF concentration at the source location, indicating a significant increase in diffusive flux through migration ports with larger cross-sections. In contrast, increasing port length (Fig. 4.4e) led to a slower decrease at the source location, indicating a more controlled diffusion through the longer migration ports. 


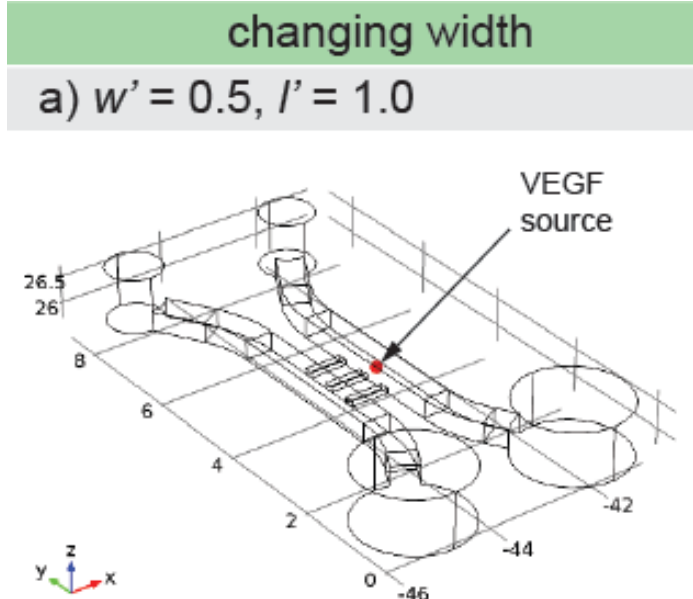
d) $w^{\prime}=1.0, l^{\prime}=0.75$

\section{changing length}

VEGF

$\ln ^{x}$

$-46$

$\mathrm{x}^{\mathrm{z}} \mathrm{x}$

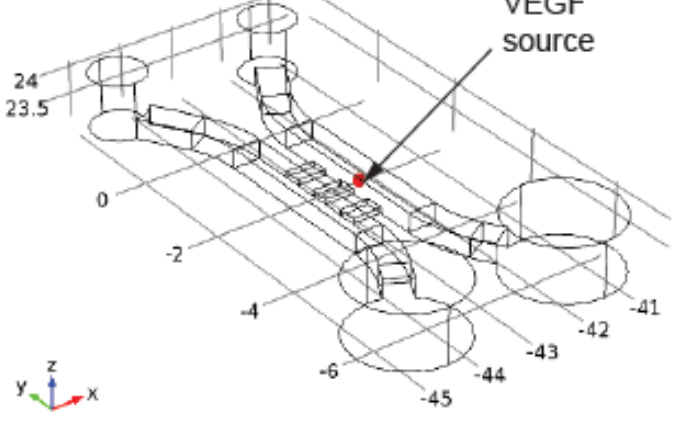

b) $w^{\prime}=1.5, l^{\prime}=1.0$

e) $w^{\prime}=1.0, l^{\prime}=1.5$
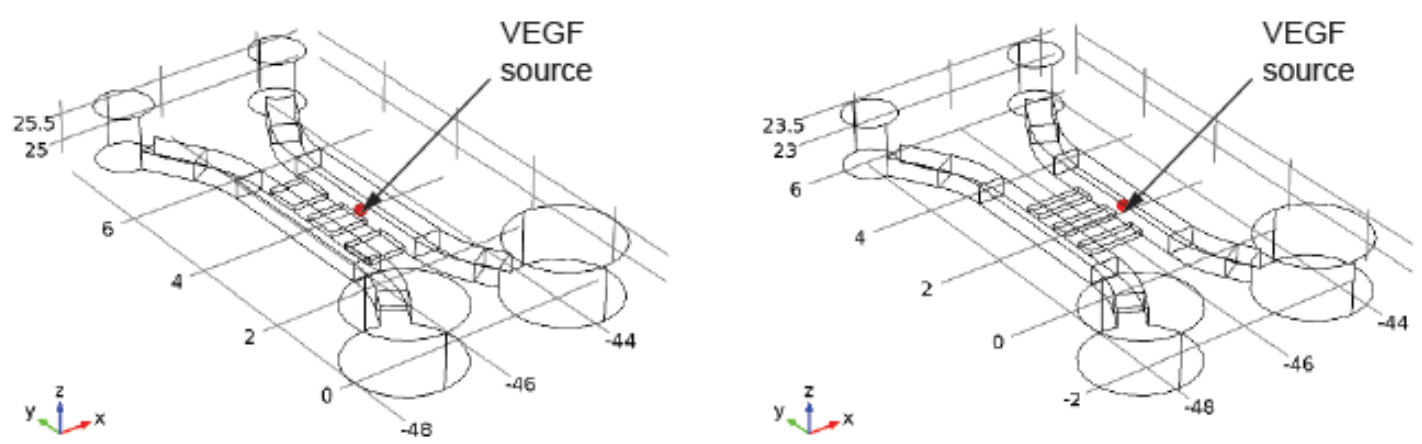

c)

\section{f)}
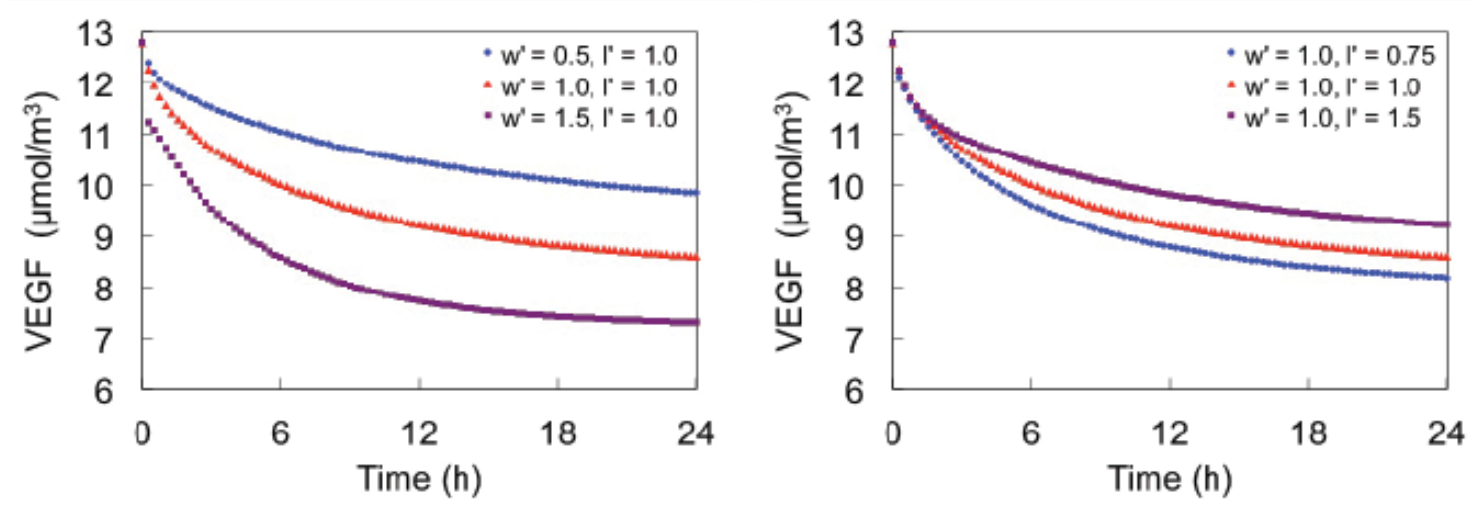

Figure 4.4. Adjusted geometries: changes in migration port width (a-c) and length (d-f). (c) VEGF concentration profiles over $24 \mathrm{~h}$, at $\mathrm{x}^{\prime}=1$ for different widths. (f) VEGF concentration profiles over $24 \mathrm{~h}$, at $\mathrm{x}^{\prime}=1$ for different lengths. 


\section{Geometric Effects on Cell Behaviour}

For different sets of migration port width and length, we employed our cell and vessel models to determine the geometric effects on migration and angiogenic sprouting behaviour. Figures 4.5 and 4.6 show the effects of changing the width for the 500-ng/mL VEGF concentration case, as predicted by the cell and vessel models, respectively.

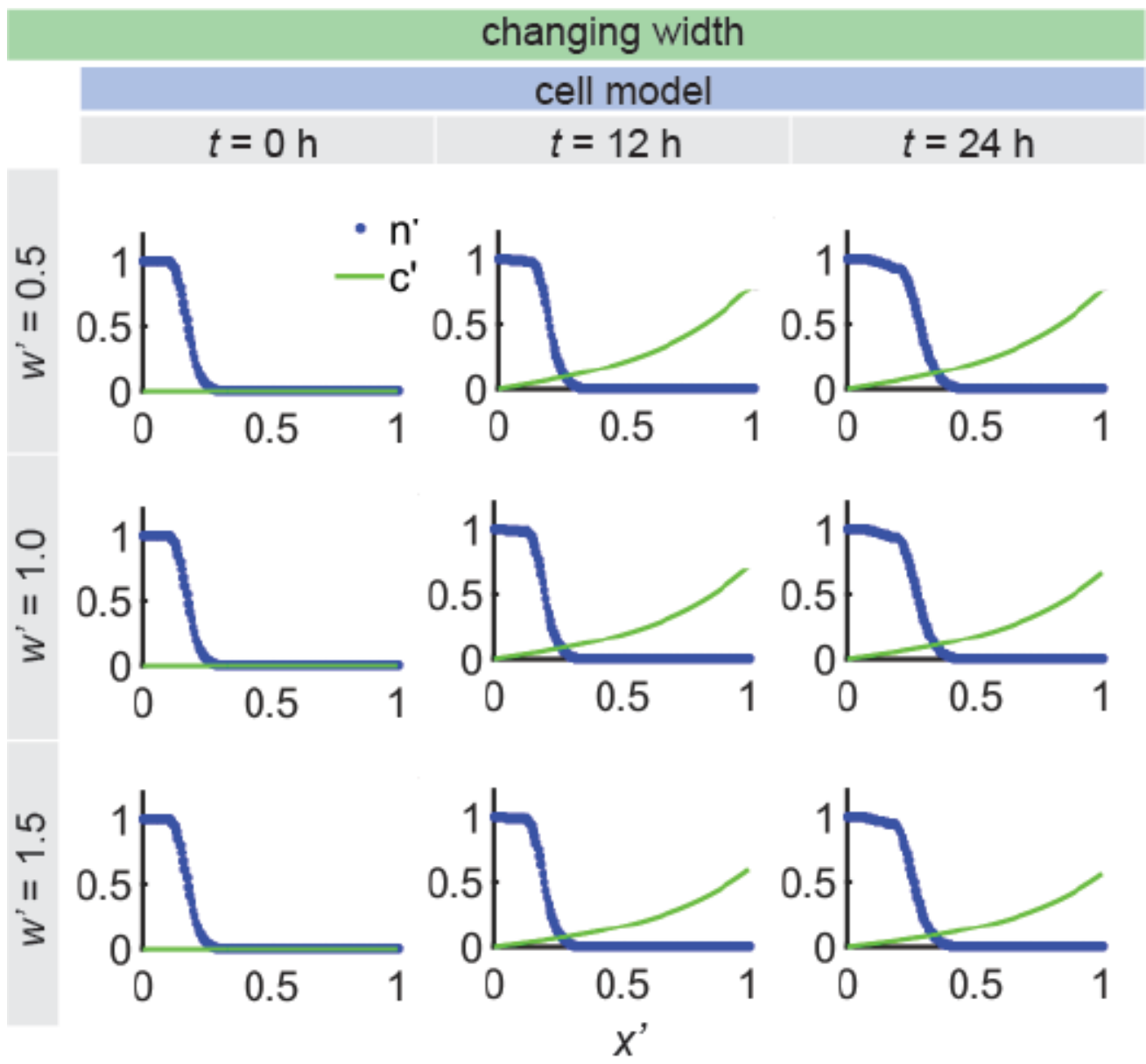

Figure 4.5. Changing widths with the cell model. Cell model chemotactic migration simulations for different migration port widths $\left(\mathrm{w}^{\prime}=0.5,1.0\right.$ and 1.5) occurring over $24 \mathrm{~h}$ with VEGF concentration at $500 \mathrm{ng} / \mathrm{mL}$. 


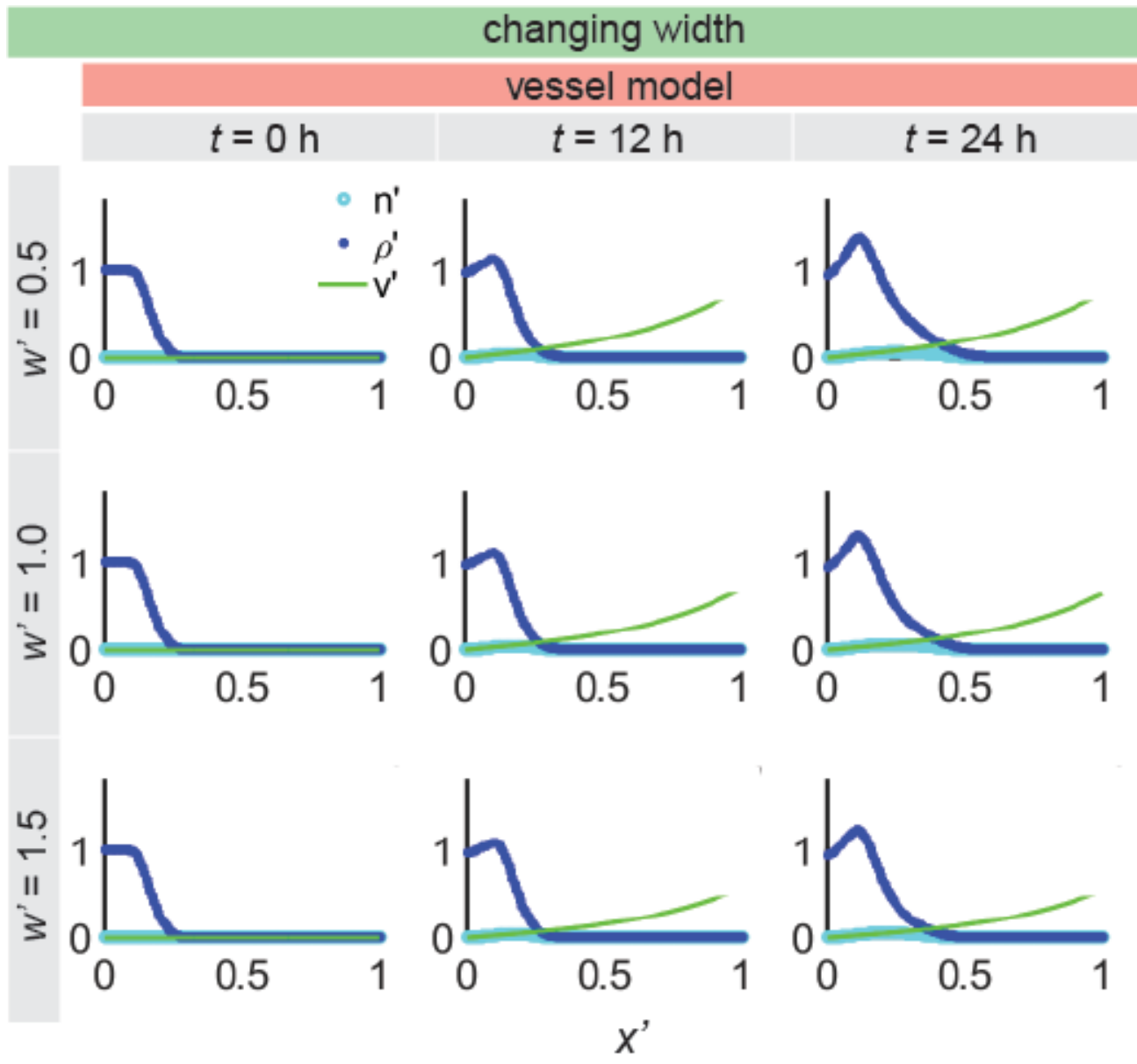

Figure 4.6. Changing widths with the vessel model. Vessel model simulations for different migration port widths ( $\mathrm{w}^{\prime}=0.5,1.0$ and 1.5 ) occurring over $24 \mathrm{~h}$ with VEGF concentration at $500 \mathrm{ng} / \mathrm{mL}$.

As mentioned, decreasing migration port width (cross section) impedes diffusion, thus leading to higher VEGF concentration at the right end of the domain $\left(x^{\prime}=1\right)$, and lower VEGF concentration at the left end $\left(x^{\prime}=0\right)$. Higher VEGF concentration means a steeper (and steadier) gradient across the migration port. Our simulations also suggest that the smallest width results in the farthest cell migration, although the increase in average migration distance is small. The vessel model also illustrates that steeper gradient results in stronger angiogenic response 
observed through higher vessel length density and farther migration. However, due to the complexity of the vessel model and the presence of other effects not present in the cell model, it may be difficult to notice the increase in migration.

Figures 4.7 and 4.8 show the effects of changing migration port length for the $500-\mathrm{ng} / \mathrm{mL}$ VEGF concentration case, as predicted by the cell and vessel models, respectively. Based on the cell model (Fig. 4.7), we observed that the optimal migration port length among the three tested cases is the $540 \mu \mathrm{m}$ length (i.e., the shortest). As expected, for the same VEGF concentration, ECs migrate at similar (but not identical) rates, and reach the right channel sooner. Importantly, these predictions could have been used as a guide during the device design stage prior to performing the actual experiments. To illustrate this point, Fig. 4.3 may be revisited, where it can be observed that cell responses for the 30 and $100 \mathrm{ng} / \mathrm{mL}$ VEGF concentration scenarios are difficult to delineate. However, if $540-\mu \mathrm{m}$ long migration ports were used instead of $720-\mu \mathrm{m}$ long migration ports, it may be hypothesized that a greater difference between the two cases may be detected, allowing effects of VEGF gradients to be pronounced. We note that the vessel model (Fig. 4.8) provides the same prediction as the cell model, with only slight differences regarding travel distance. Hence, both models predict that the optimal migration length for detecting angiogenesis after 24-h of $500 \mathrm{ng} / \mathrm{mL}$ VEGF exposure (in terms of providing the most information) is the $540-\mu \mathrm{m}$ length. 


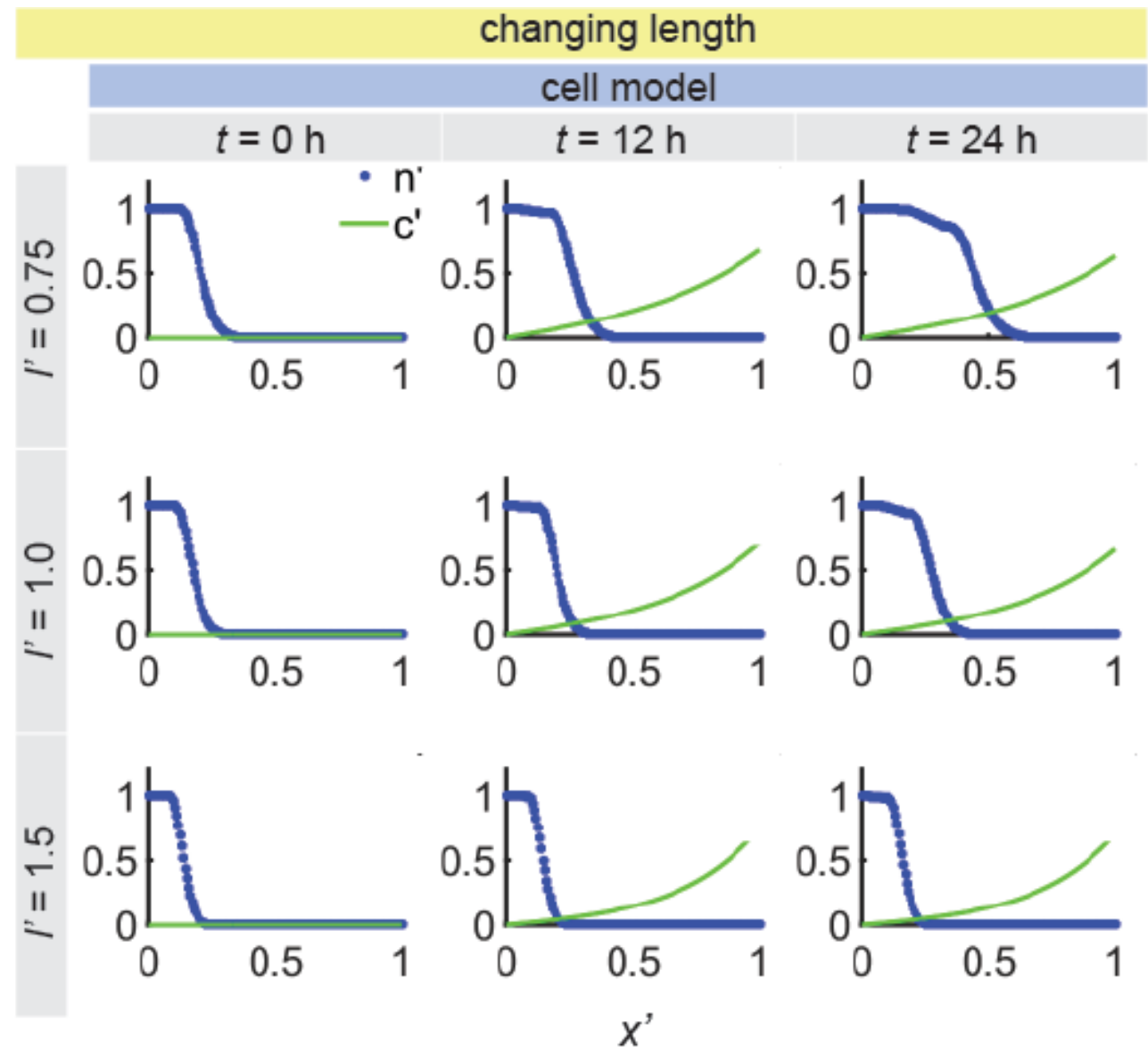

Figure 4.7. Changing lengths with the cell model. Cell model simulations for different migration port lengths $\left(l^{\prime}=0.75,1.0\right.$ and 1.5$)$ occurring over $24 \mathrm{~h}$ with VEGF concentration at $500 \mathrm{ng} / \mathrm{mL}$. 


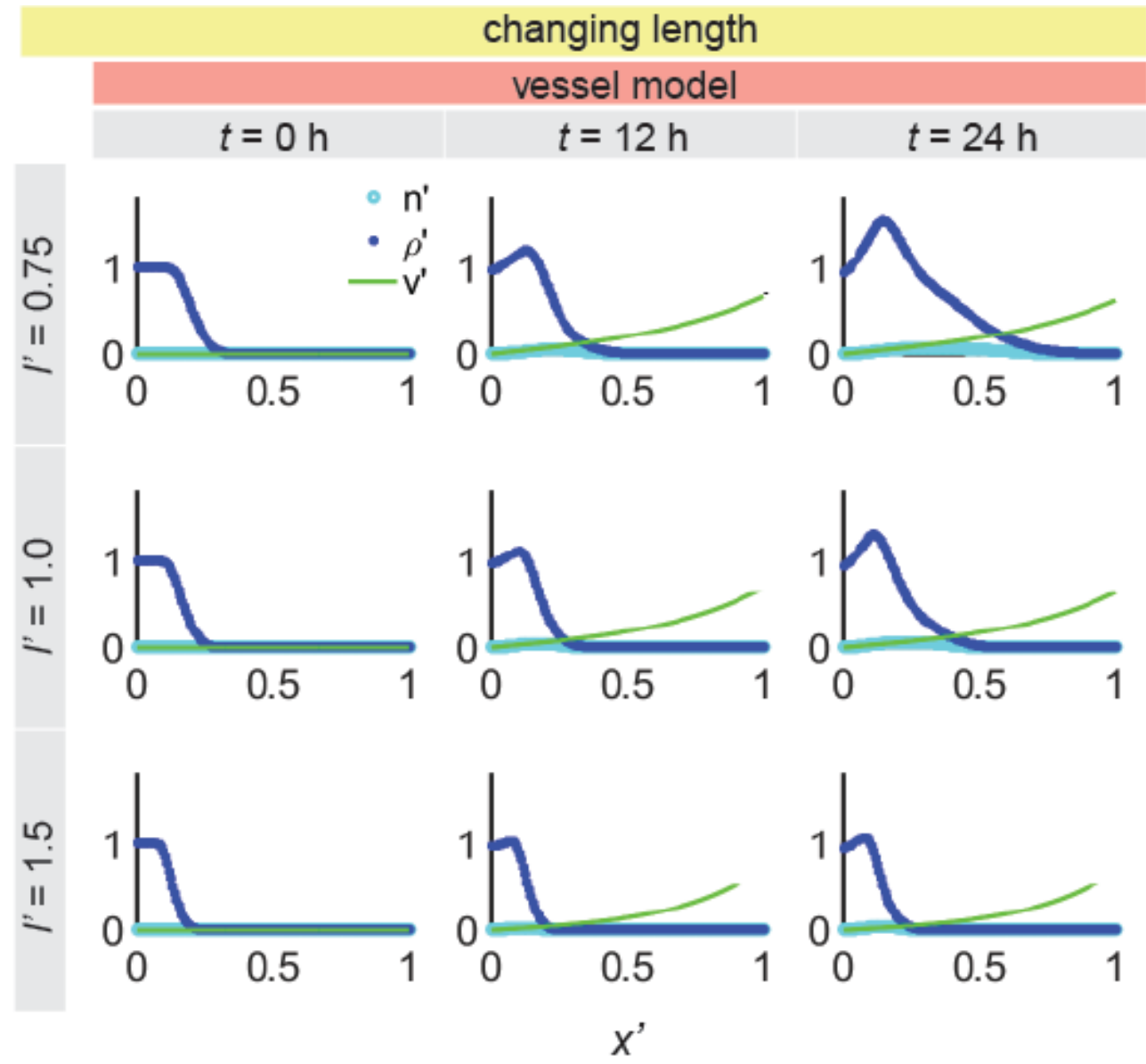

Figure 4.8. Changing lengths with the vessel model. Vessel model simulations for different migration port lengths $\left(l^{\prime}=0.75,1.0\right.$ and 1.5$)$ occurring over $24 \mathrm{~h}$ with VEGF concentration at $500 \mathrm{ng} / \mathrm{mL}$.

To summarize the findings regarding changing widths and lengths of migration ports, we plotted on the same graph EC migration (the cell model) and angiogenesis (the vessel model) at $24 \mathrm{~h}$ under $500 \mathrm{ng} / \mathrm{mL}$ VEGF concentration. 

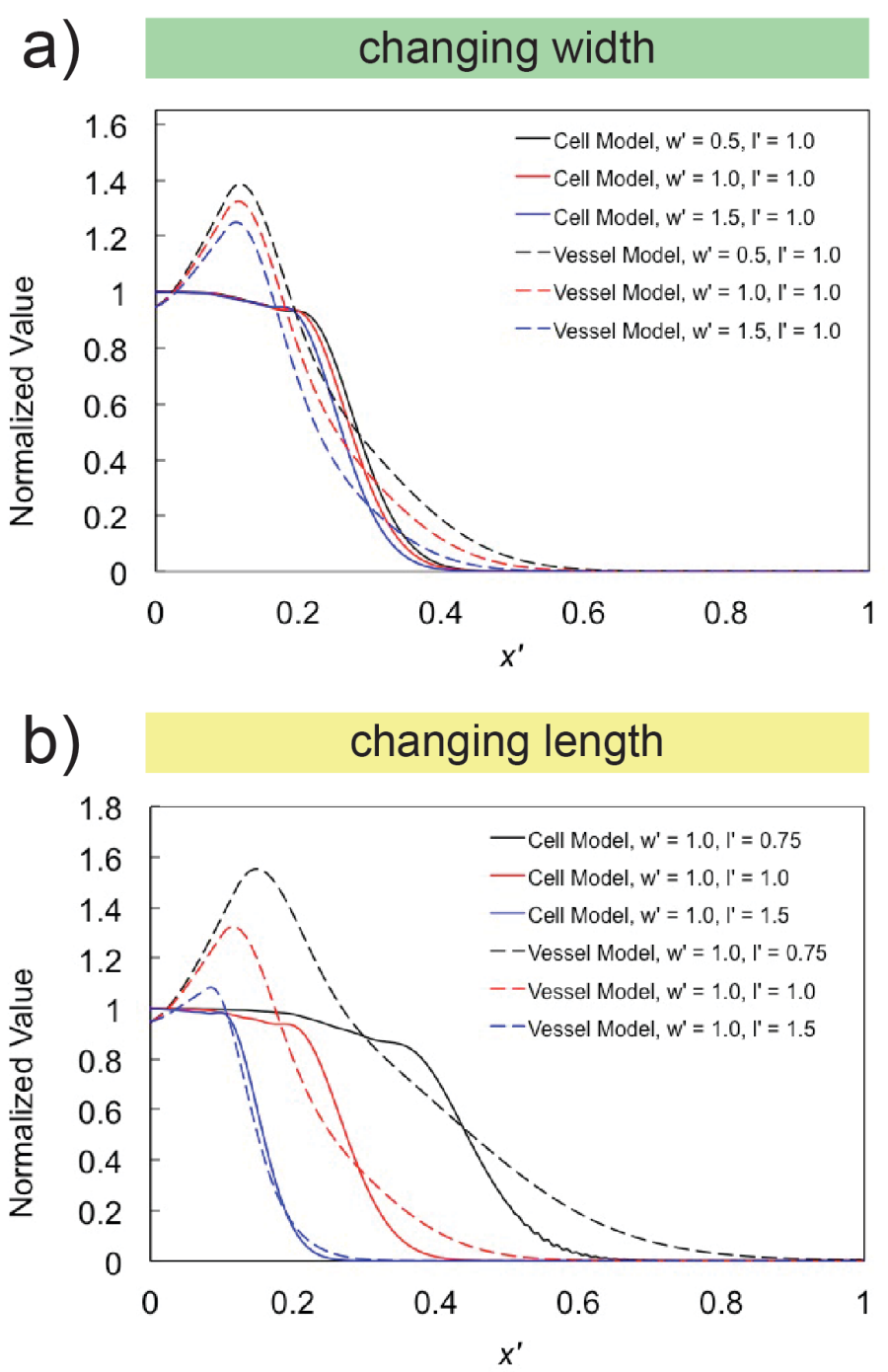

Figure 4.9. Assessing geometric features potential to enhance angiogenesis. Three different diffusion port widths (top) and lengths (bottom).

Although varying cross-sectional area can impede (or facilitate) diffusion, width did not appear to play a major role in affecting migration an angiogenesis for this specific VEGF concentration range $(30-500 \mathrm{ng} / \mathrm{mL})$. In contrast, length plays a significant role in enhancing angiogenesis due its strong effect on the gradient. This is in accordance with Fick's law of diffusion, as shorter distances will establish steeper gradients, and therefore result in most prominent cell response. 
Hence, we hope that these findings will serve as a design guide for the microfluidic community and provide computational basis that will improve current and future cell migration assays. 


\section{Chapter 5}

\section{Conclusions and Future Work}

Angiogenesis is the key process that enables tumour growth past the avascular stage and metastasis. Hence, understanding angiogenesis is an important step in improving treatment plans and putting cancer into remission. High costs and ethical issues associated with animal testing has motivated researchers to develop highly accessible and controllable microfluidic devices for studying angiogenesis with better physiological relevance than conventional in vitro assays. Unfortunately, researchers often rely on trial-and-error approach at the beginning of the microfluidic device design process which is inefficient, time consuming and costly. In this work, we have tailored two existing mathematical models for EC migration and angiogenesis with the aim to create computational framework that could provide guidance with regards to geometric feature selection. More specifically, we have simulated chemotactic migration and angiogenesis inside the static diffusion microfluidic device under 30,100 and $500 \mathrm{ng} / \mathrm{mL}$ VEGF concentrations over a $24 \mathrm{~h}$ period. The models were successfully validated against experimental data and suggested potential ways of optimizing currently used devices.

In the future, these models can be extended to study effects of drugs in conjunction with additional growth factors as well as migration of other cells. Microfluidics has the opportunity to improve current drug development and testing by providing insight into effectiveness of potential drug candidates early in the process and significantly reduce the development time and costs. To achieve this goal, the devices need to be optimized to provide appropriate gradients and concentration levels of various growth factors together with physiologically relevant drug concentrations. Computational modelling has a lot to offer to this end and our approach can be 
extended to include various factors such as FGF and ANG-2, and study them in conjunction with anti-angiogenesis drugs. Furthermore, besides the HUVECs, the model can be extended to study migration of different types of ECs and can be applied to coculture systems. The classic approach would be to treat tumour cells as sources of growth factors but due to their invasiveness in coculture systems, additional variables and appropriate BCs would need to be implemented. 


\section{References}

[1] Cross MJ, Claesson-Welsh L. "FGF and VEGF function in angiogenesis: signalling pathways, biological responses and therapeutic inhibition." Trends Pharmacol. Sci., 22(4), 201-207 (2001).

[2] Baeriswyl V, Christofori G. "The angiogenic switch in carcinogenesis." Semin. Cancer Biol., 19(5), 329-337 (2009).

[3] Goel S, Duda DG, Xu L, Munn LL, Boucher Y, Fukumura D et al. "Normalization Of The Vasculature For Treatment Of Cancer And Other Diseases." Physiol. Rev., 91(3), 1071$1121(2011)$.

[4] Carmeliet P, Jain R. "Angiogenesis in cancer and other diseases." Nature, 407(6801), 249-257 (2000).

[5] Duran C, Howell DW, Dave, J.M., Smith R.L., Torrie, M.E., Essner, J.J., Bayless KJ. "Molecular Regulation of Sprouting Angiogenesis." Compr Physiol. 8(1): 153-235 (2017).

[6] Miles FL, Pruitt FL, Van Golen KL, Cooper CR. "Stepping out of the flow: Capillary extravasation in cancer metastasis." Clin. Exp. Metastasis, 25(4), 305-324 (2008).

[7] DeCicco-Skinner KL, Henry GH, Cataisson C, Tabib T, Gwilliam JC, Watson NJ et al. "Endothelial Cell Tube Formation Assay for the In Vitro Study of Angiogenesis." J. Vis. Exp., 10(91), 1-8 (2014).

[8] Boyden S. "The Chemotactic Effect of Mixtures of Antibody and Antigen on Polymorphonuclear Leucocytes." J. Exp. Med., 115(3), 453-466 (1962).

[9] Timmins N, Dietmair S, Nielsen L. "Hanging-drop multicellular spheroids as a model of tumour angiogenesis." Angiogenesis, 7(2), 97-103 (2004).

[10] Rogers MS, Birsner AE, D’Amato RJ. "The mouse cornea micropocket angiogenesis assay." Nat. Protoc., 2(10), 2545-2550 (2007). 
[11] Auerbach R, Lewis R, Shinners B, Kubai L, Akhtar N. "Angiogenesis assays: A critical overview." Clin. Chem., 49(1), 32-40 (2003).

[12] Young EWK. "Advances in microfluidic cell culture systems for studying angiogenesis." $J A L A, 18(6), 427-436$ (2013).

[13] Kim BJ, Wu M. "Microfluidics for Mammalian Cell Chemotaxis." Annu. Biomed Eng., 40(6), 1316-1327 (2012).

[14] Kim S, Kim HJ, Jeon NL. "Biological applications of microfluidic gradient devices." Integr. Biol., 2(11-12), 584-603 (2010).

[15] Abhyankar V V., Toepke MW, Cortesio CL, Lokuta MA, Huttenlocher A, Beebe DJ. "A platform for assessing chemotactic migration within a spatiotemporally defined 3D microenvironment." Lab Chip, 8(9), 1507-1515 (2008).

[16] Shamloo A, Ma N, Poo M, Sohn LL, Heilshorn SC. "Endothelial cell polarization and chemotaxis in a microfluidic device." Lab Chip, 8(8), 1292 (2008).

[17] Haessler U, Pisano M, Wu M, Swartz MA. "Dendritic cell chemotaxis in 3D under defined chemokine gradients reveals differential response to ligands CCL21 and CCL19." Proc. Natl. Acad. Sci., 108(14), 5614-5619 (2011).

[18] Bischel LL, Young EWK, Mader BR, Beebe DJ. "Tubeless microfluidic angiogenesis assay with three-dimensional endothelial-lined microvessels." Biomaterials, 34(5), 14711477 (2013).

[19] Song JW, Munn LL. "Fluid forces control endothelial sprouting." Proc. Natl. Acad. Sci. U. S. A., 108(37), 15342-15347 (2011).

[20] Song JW, Bazou D, Munn LL. "Anastomosis of endothelial sprouts forms new vessels in a tissue analogue of angiogenesis." Integr Biol, 4(8), 857-862 (2012).

[21] Vickerman V, Chung S, Kamm RD. "Design, Fabrication and Implementation of a Novel Multi Parameter Control Microfluidic Platform for Three-Dimensional Cell Culture and 
Real-Time Imaging." Lab Chip, 8(9), 1468-1477 (2008).

[22] Kim S, Lee H, Chung M, Jeon NL. "Engineering of functional, perfusable 3D microvascular networks on a chip." Lab Chip, 13, 1489-1500 (2013).

[23] Theberge AB, Yu J, Young EWK, Ricke WA, Bushman W, Beebe DJ. "Microfluidic Multiculture Assay to Analyze Biomolecular Signaling in Angiogenesis." Anal. Chem., 87(6), 3239-3246 (2015).

[24] Scianna M, Bell CG, Preziosi L. "A review of mathematical models for the formation of vascular networks." J. Theor. Biol., 333, 174-209 (2013).

[25] Deakin AS. "Model for initial vascular patterns in melanoma transplants." Growth, 40(2), 191-201 (1976).

[26] Balding D, McElwain DLS. "A mathematical model of tumour-induced capillary growth." J. Theor. Biol., 114(1), 53-73 (1985).

[27] Edelstein L. "The propagation of fungal colonies: a model for tissue growth." J. Theor. Biol., 98(4), 679-701 (1982).

[28] Chaplain MAJ, Stuart AM. "A model mechanism for the chemotactic response of endotheliai cells to tumour angiogenesis factor." IMA J. Math. Appl. Med. Biol., 10(December), 149-168 (1993).

[29] Byrne HM, Chaplain MAJ. "Explicit solutions of a simplified model of capillary sprout growth during tumour angiogenesis." Appl. Math. Lett., 8(5), 71-76 (1995).

[30] Muthukkaruppan VR, Kubai L, Auerbach R. "Tumor-induced neovascularization in the mouse eye." J. Natl. Cancer Inst., 69(3), 699-708 (1982).

[31] Orme ME, Chaplain MAJ. "Two-dimensional models of tumour angiogenesis and antiangiogenesis strategies." IMA J. Math. Appl. Med. Biol., 14(3), 189-205 (1997).

[32] Anderson ARA, Chaplain MAJ. "Continuous and discrete mathematical models of tumorinduced angiogenesis." Bull. Math. Biol., 60(5), 857-899 (1998). 
[33] Levine HA, Pamuk S, Sleeman BD, Nilsen-Hamilton M. "Mathematical modeling of capillary formation and development in tumor angiogenesis: Penetration into the stroma." Bull. Math. Biol., 63(5), 801-863 (2001).

[34] Plank MJ, Sleeman BD. "A reinforced random walk model of tumour angiogenesis and anti - angiogenic strategies." Math. Med. Biol., 20(July), 135-181 (2003).

[35] Holmes MJ, Sleeman BD. "A mathematical model of tumour angiogenesis incorporating cellular traction and viscoelastic effects." J. Theor. Biol., 202(2), 95-112 (2000).

[36] Di Costanzo E, Ingangi V, Angelini C, Carfora MF, Carriero MV, Natalini R. "A macroscopic mathematical model for cell migration assays using a real-time cell analysis." PLoS One, 11(9), 1-20 (2016).

[37] Serini G, Ambrosi D, Giraudo E, Gamba A, Preziosi L, Bussolino F. "Modeling the early stages of vascular network assembly." EMBO J., 22(8), 1771-1779 (2003).

[38] Gamba A, Ambrosi D, Coniglio A, de Candia A, Di Talia S, Giraudo E et al. "Percolation, Morphogenesis, and Burgers Dynamics in Blood Vessels Formation." Phys. Rev. Lett., 90(11), 4 (2003).

[39] Connor AJ, Nowak RP, Lorenzon E, Thomas M, Herting F, Hoert S et al. "An integrated approach to quantitative modelling in angiogenesis research." J. R. Soc. Interface, 12(110), 1-29 (2015).

[40] Stokes CL, Laudenburger DA. "Analysis of the roles of microvessel endothelial cell random motility and cehmotaxis in angiogenesis." J. Theo. Biol., 152, 377-403 (1991).

[41] Stokes CL, Lauffenburger DA, Williams SK. "Migration of individual microvessel endothelial cells: stochastic model and parameter measurement." J Cell Sci, 99, 419-430 (1991).

[42] Hill NA, Häder DP. "A biased random walk model for the trajectories of swimming micro-organisms." J. Theor. Biol., 186(4), 503-526 (1997). 
[43] Milde F, Bergdorf M, Koumoutsakos P. "A hybrid model for three-dimensional simulations of sprouting angiogenesis." Biophys. J., 95(7), 3146-3160 (2008).

[44] Bentley K, Mariggi G, Gerhardt H, Bates PA. "Tipping the balance: Robustness of tip cell selection, migration and fusion in angiogenesis." PLoS Comput. Biol., 5(10), e1000549 (2009).

[45] Graner F, Glazier JA. "Simulation of biological cell sorting using a two-dimensional extended Potts model." Phys. Rev. Lett., 69(13), 2013-2016 (1992).

[46] Bauer AL, Jackson TL, Jiang Y. "A cell-based model exhibiting branching and anastomosis during tumor-induced angiogenesis." Biophys. J., 92(9), 3105-3121 (2007).

[47] Chaplain MAJ. "Mathematical Modelling of Angiogenesis." J. Neuro-Oncology, 37-51 (2000).

[48] McDougall SR, Anderson ARA, Chaplain MAJ. "Mathematical modelling of dynamic adaptive tumour-induced angiogenesis: Clinical implications and therapeutic targeting strategies." J. Theor. Biol., 241(3), 564-589 (2006).

[49] Tong S, Yuan F. "Numerical simulations of angiogenesis in the cornea." Microvasc. Res., 61(1), 14-27 (2001).

[50] Harrington HA, Maier M, Naidoo L, Whitaker N, Kevrekidis PG. "A hybrid model for tumor-induced angiogenesis in the cornea in the presence of inhibitors." Math. Comput. Model., 46(3-4), 513-524 (2007).

[51] Tong S, Yuan F. "Dose response of angiogenesis to basic fibroblast growth factor in rat corneal pocket assay: II. Numerical simulations." Microvasc. Res., 75(1), 16-24 (2008).

[52] Das A, Lauffenburger D, Asada H, Kamm RD. "A hybrid continuum-discrete modelling approach to predict and control angiogenesis: Analysis of combinatorial growth factor and matrix effects on vessel-sprouting morphology." Philos. Trans. R. Soc. A Math. Phys. Eng. Sci., 368(1921), 2937-2960 (2010). 
[53] Travasso RDM, Corvera Poiré E, Castro M, Rodrguez-Manzaneque JC, HernándezMachado A. "Tumor Angiogenesis and Vascular Patterning: A Mathematical Model." PLoS One, 6(5), e19989 (2011).

[54] Vilanova G, Colominas I, Gomez H. "A mathematical model of tumour angiogenesis: Growth, regression and regrowth." J. R. Soc. Interface, 14(126), 20160918 (2017).

[55] Alnaes, M. S., Blechta, J., Hake, J., Johansson, A., Kehlet, B., Logg, A., Richardson, C., Ring, J., Rognes, M.E., Wells GN. "The FEniCS Project Version 1.5." Arch. Numer. Softw., https://fenicsproject.org/.

[56] Grogan J. "Microvessel CHASTE." https://jmsgrogan.github.io/MicrovesselChaste/docu (2018).

[57] Owen MR, Alarcón T, Maini PK, Byrne HM. "Angiogenesis and vascular remodelling in normal and cancerous tissues." J. Math. Biol., 58(4-5), 689-721 (2009).

[58] Sadiku MNO, Obiozor CN. "A Simple Introduction to the Method of Lines." Int. J. Electr. Eng. Educ., 37(3), 282-296 (2000).

[59] Chen RR, Silva EA, Yuen WW, Mooney DJ. "Spatio-temporal VEGF and PDGF delivery patterns blood vessel formation and maturation." Pharm. Res., 24(2), 258-264 (2007).

[60] Gabhann F Mac, Popel AS. "Differential binding of VEGF isoforms to VEGF receptor 2 in the presence of neuropilin-1: a computational model." Am. J. Physiol. - Hear. Circ. Physiol., 288(6), H2851-H2860 (2005).

[61] Ambrosi D, Bussolino F, Preziosi L. "A review of vasculogenesis models." J. Theor. Med., 6(1), 1-19 (2005).

[62] Sherratt AJ, Murray JD. "Models of Epidermal Wound Healing." Proc. R. Soc. London B, 241(1300), 29-36 (1990).

[63] Addison-Smith B. "Mathematical Modelling of Tumour-Induced Angiogenesis." PhD Thesis (2010). 
[64] Akeson A, Herman A, Wiginton D, Greenberg J. "Endothelial cell activation in a VEGFA gradient: Relevance to cell fate decisions." Microvasc. Res., 80(1), 65-74 (2010).

[65] Wang D, Lehman RE, Donner DB, Matli MR, Warren RS, Welton ML. "Expression and endocytosis of VEGF and its receptors in human colonic vascular endothelial cells." Am. J. Physiol. Liver Physiol., 282(6), G1088-G1096 (2002).

[66] Cao R, Brakenhielm E, Wahlberg E, Leboulch P, Cao Y. "Angiogenic synergism, vascular stability and improvement of hin-limb ischemia bya combination of PDGF-BB and FGF2." Nat Med, 9(5), 548-553 (2003). 


\section{Appendices}

We would like to express our gratitude to computational biology researchers from Oxford University for making their code open-source. We extended methodology proposed in Connor et al. [39]. Furthermore, graphing tools utilize source code found at http://www.che.utah.edu/department_documents/Projects_Lab/Projects_Lab_Handbook/MatlabP lots.pdf.

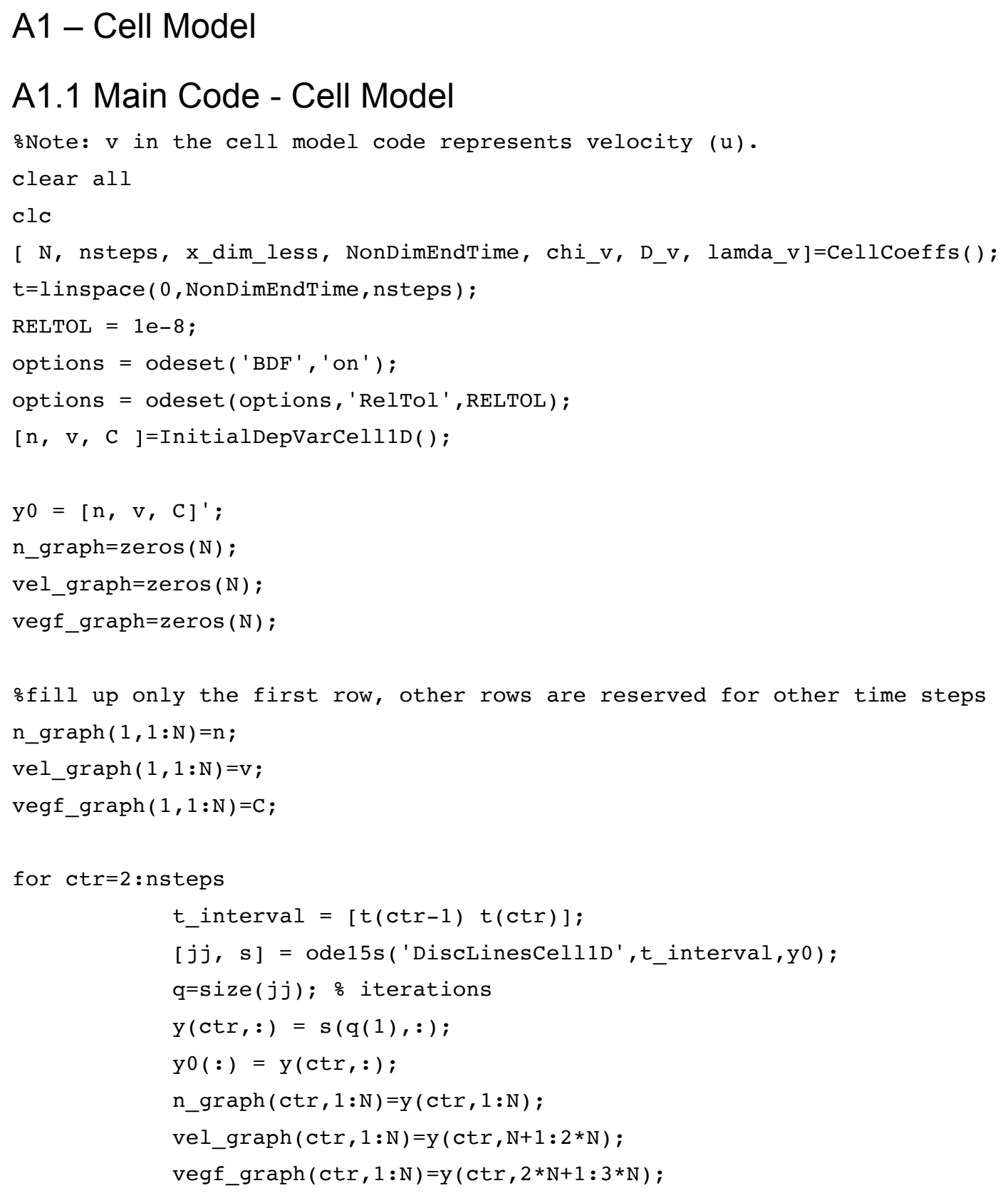




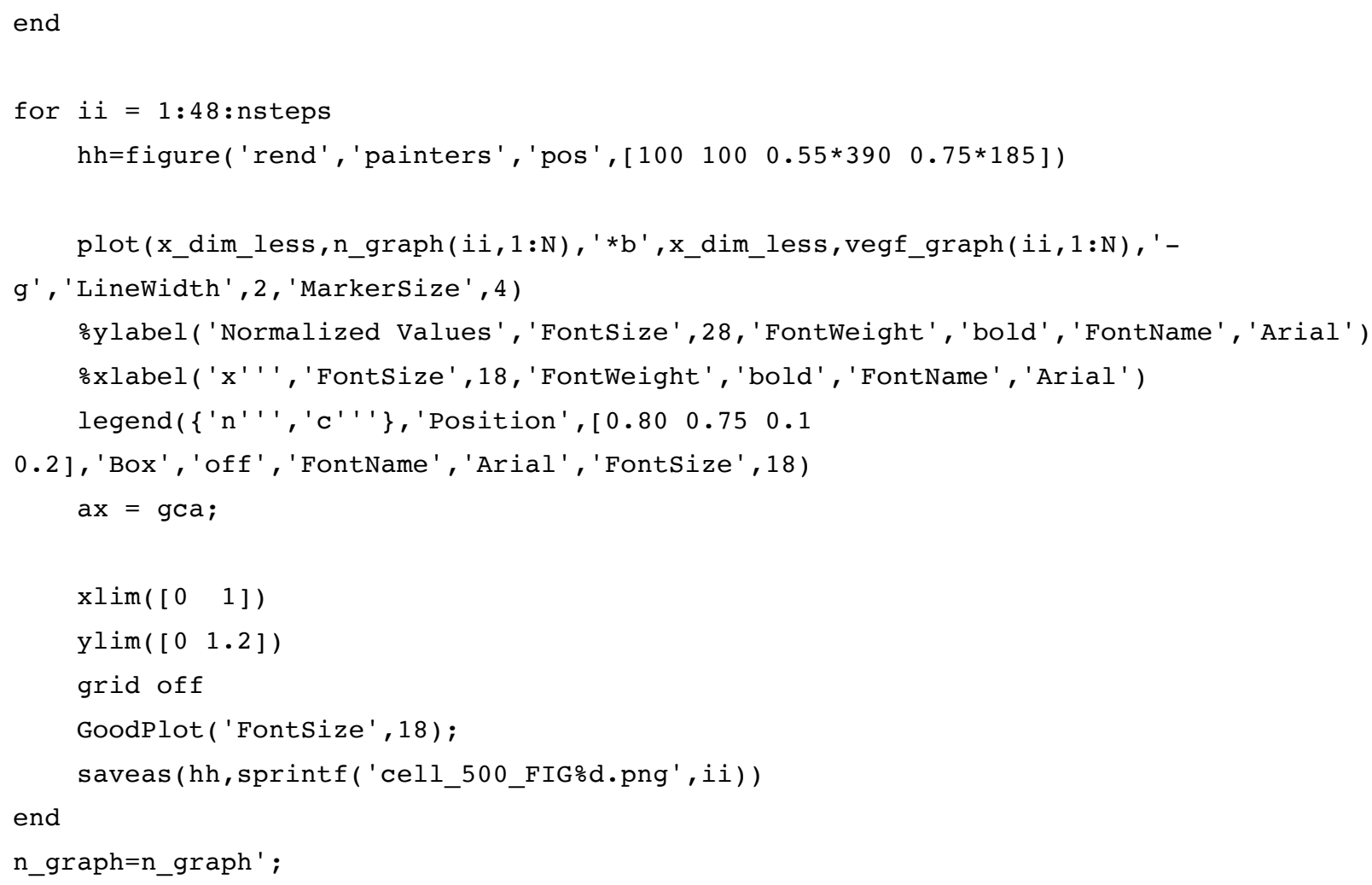

\section{A1.2 Method of Lines Discretization - Cell Model}

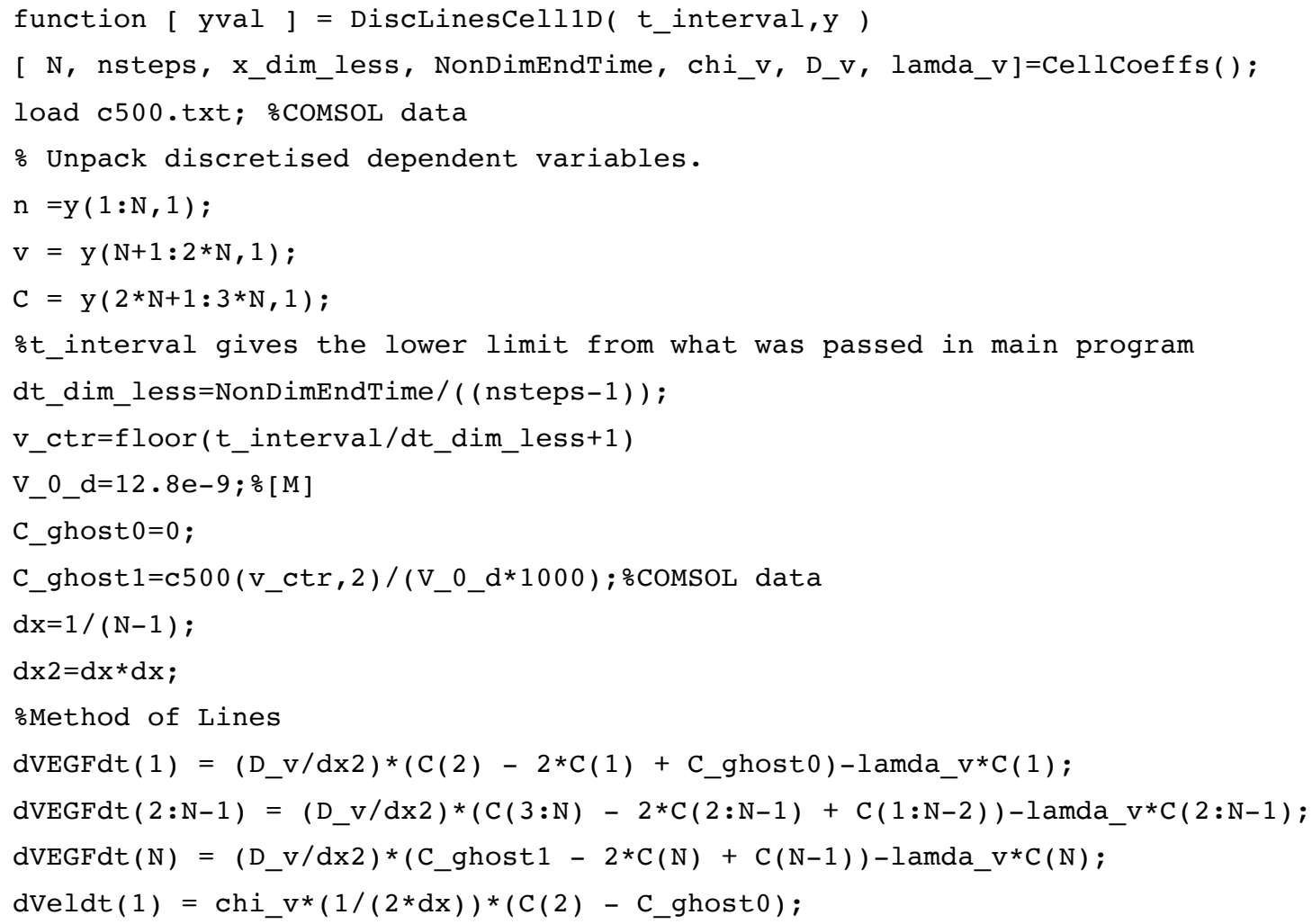


$\operatorname{dVeldt}(2: \mathrm{N}-1)=\operatorname{chi} \mathrm{v}^{*}(1 /(2 * \mathrm{dx})) *(\mathrm{C}(3: \mathrm{N})-\mathrm{C}(1: \mathrm{N}-2))-\mathrm{v}(2: \mathrm{N}-1) \cdot *((\mathrm{v}(3: \mathrm{N})-\mathrm{v}(1: \mathrm{N}-$

2)) / $(2 * d x))$;

$\operatorname{dVeldt}(\mathrm{N})=\operatorname{chi} \mathrm{v}^{*}(1 /(2 * \mathrm{dx})) *\left(\mathrm{C}_{-}\right.$ghost1 $\left.-\mathrm{C}(\mathrm{N}-1)\right)$;

$\operatorname{dndt}(1)=0$;

$\operatorname{dndt}(2: \mathrm{N}-1)=-\mathrm{v}(2: \mathrm{N}-1) \cdot *((\mathrm{n}(3: \mathrm{N})-\mathrm{n}(1: \mathrm{N}-2)) /(2 * \mathrm{dx}))-\mathrm{n}(2: \mathrm{N}-1) \cdot *((\mathrm{v}(3: \mathrm{N})-\mathrm{v}(1: \mathrm{N}-$

2)) / $(2 * d x))$;

$\operatorname{dndt}(\mathrm{N})=0$;

yval $=[$ dndt, dVeldt, dVEGFdt ] ' ;

end

\section{A1.3 Non-dimensionalization Function - Cell Model}

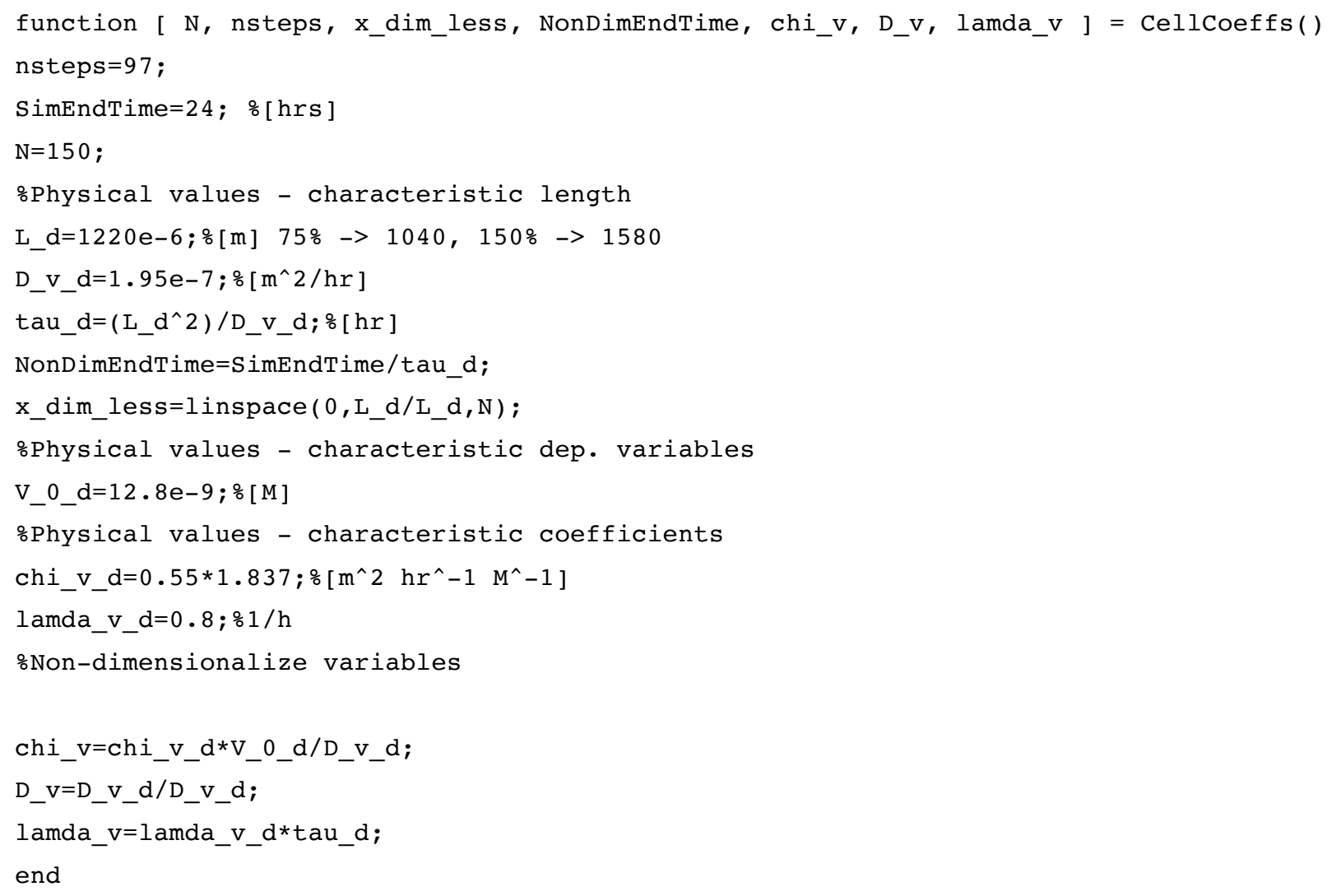

A1.4 Initialization of Dependent Variables - Cell Model

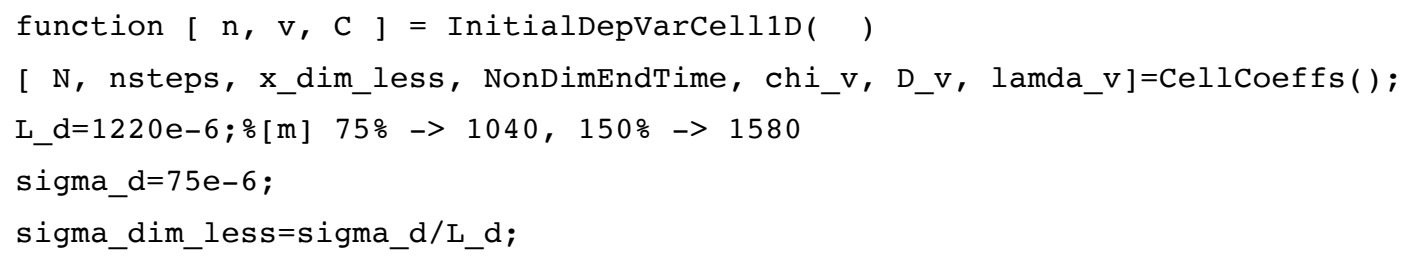




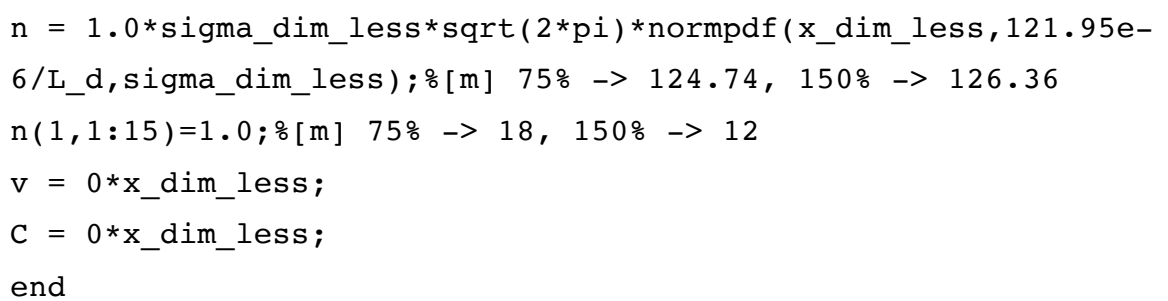

A2 - Vessel Model

A2.1 Main Code - Vessel Model

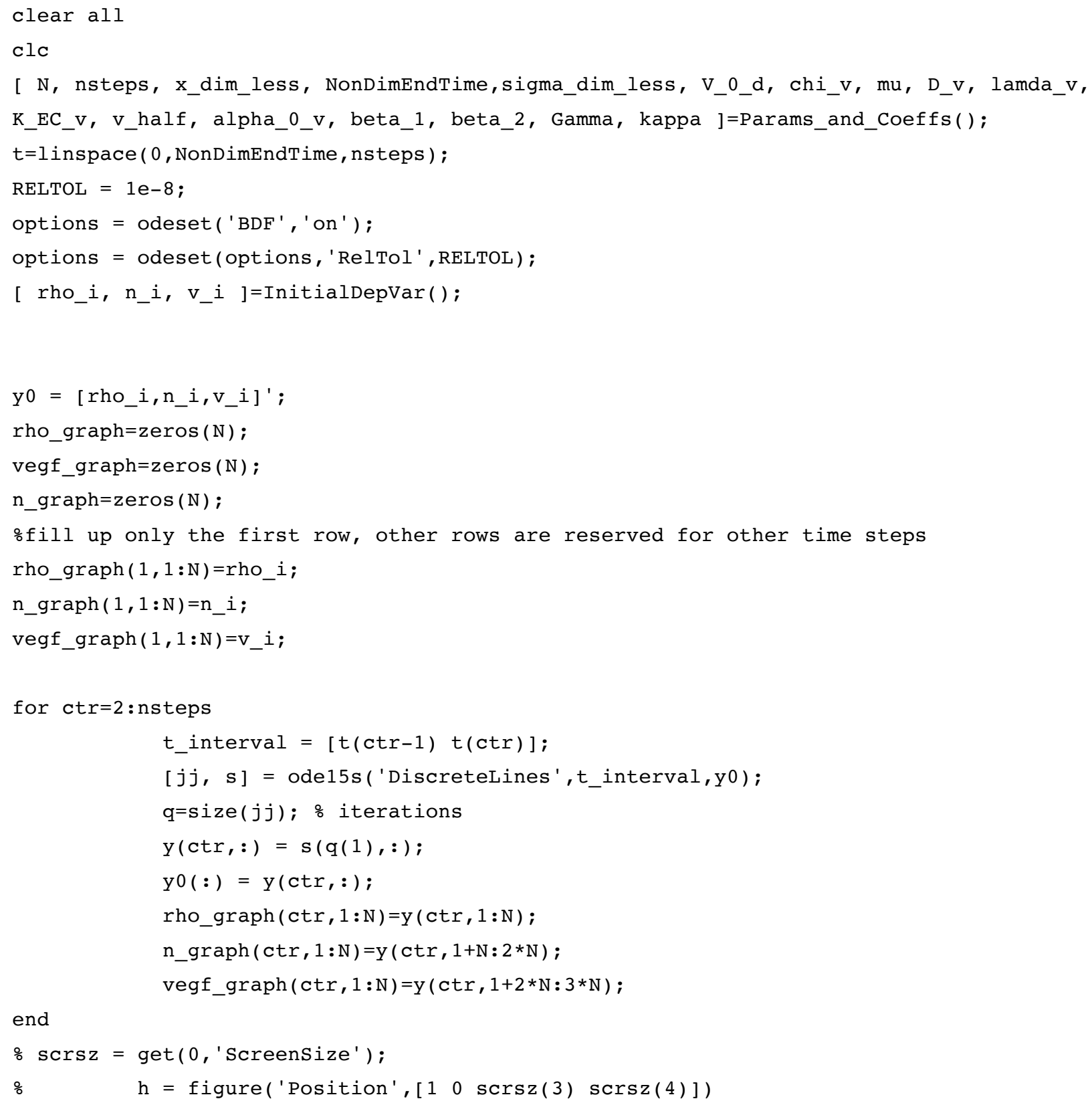




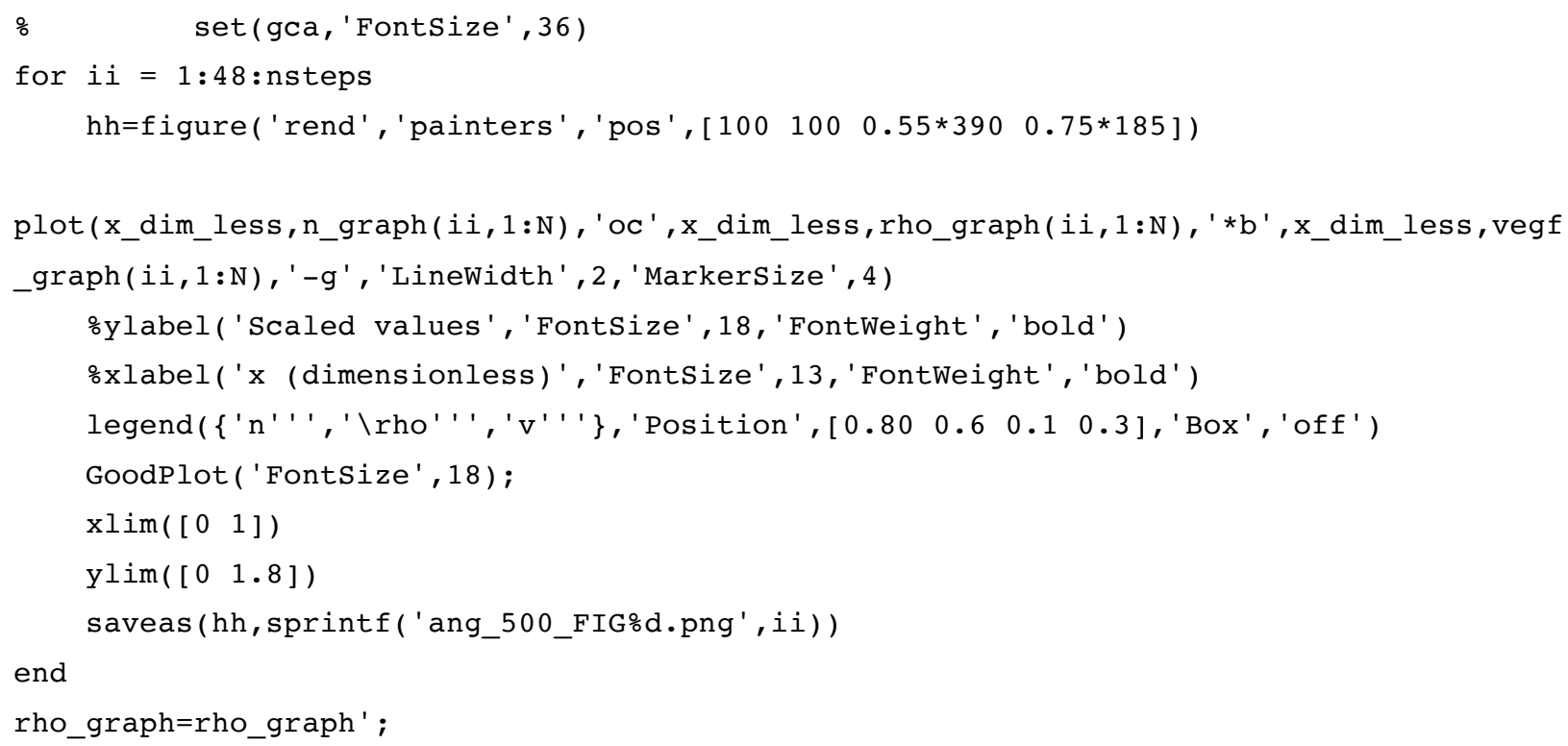

\section{A2.2 Method of Lines Discretization - Vessel Model}

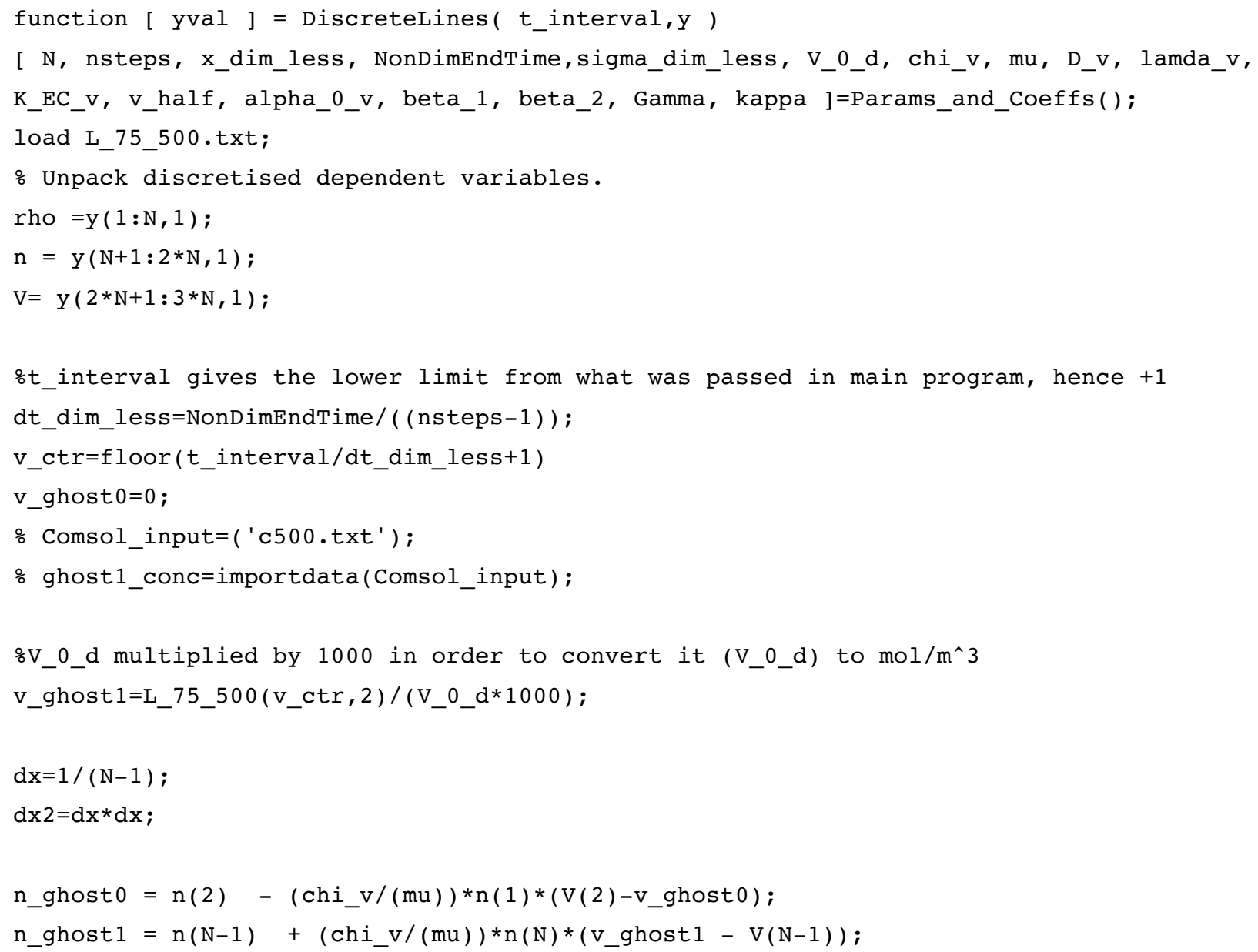




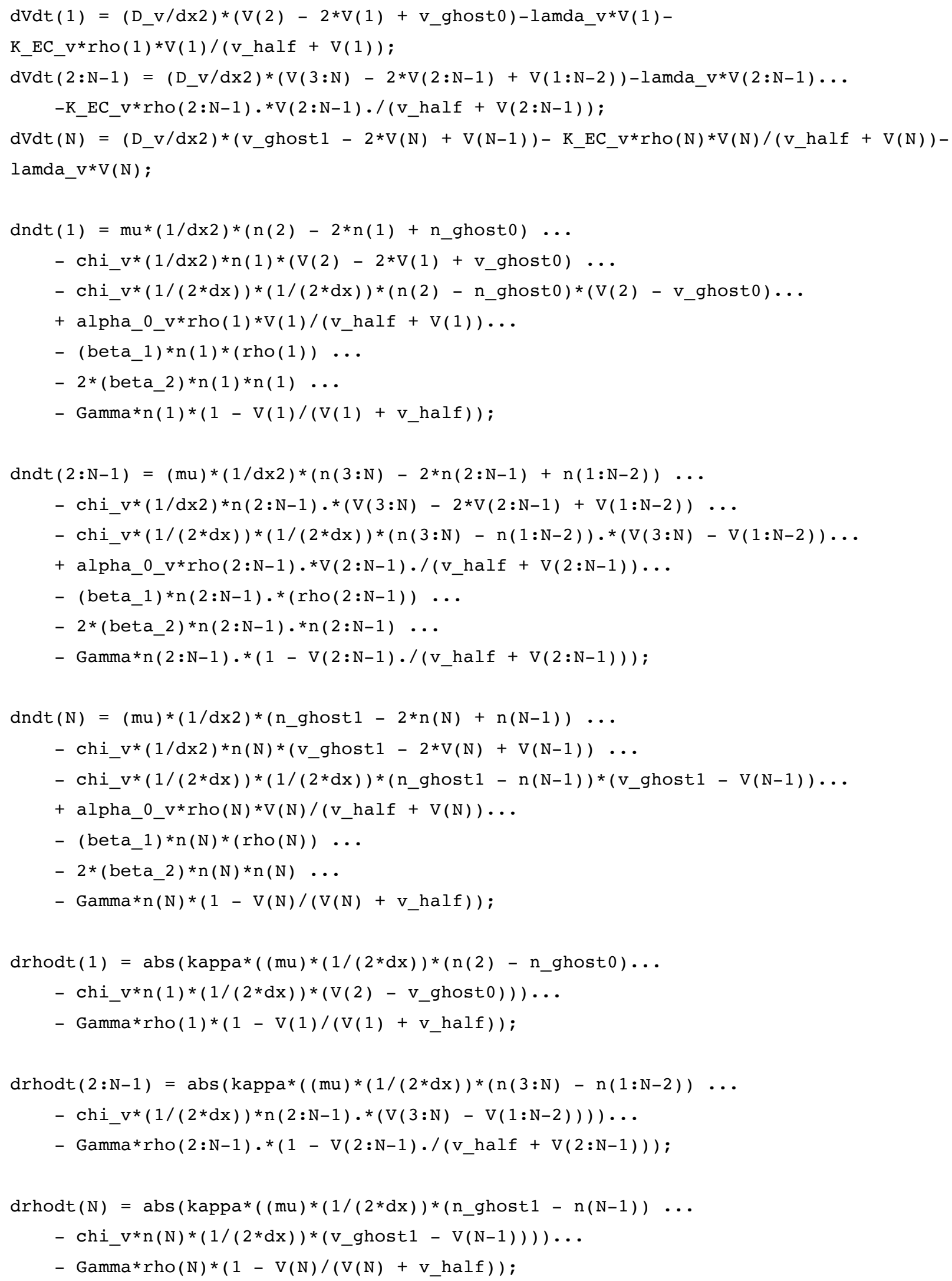


yval $=[$ drhodt, dndt, dVdt ] ' ;

end

\section{A2.3 Non-dimensionalization Function - Vessel Model}

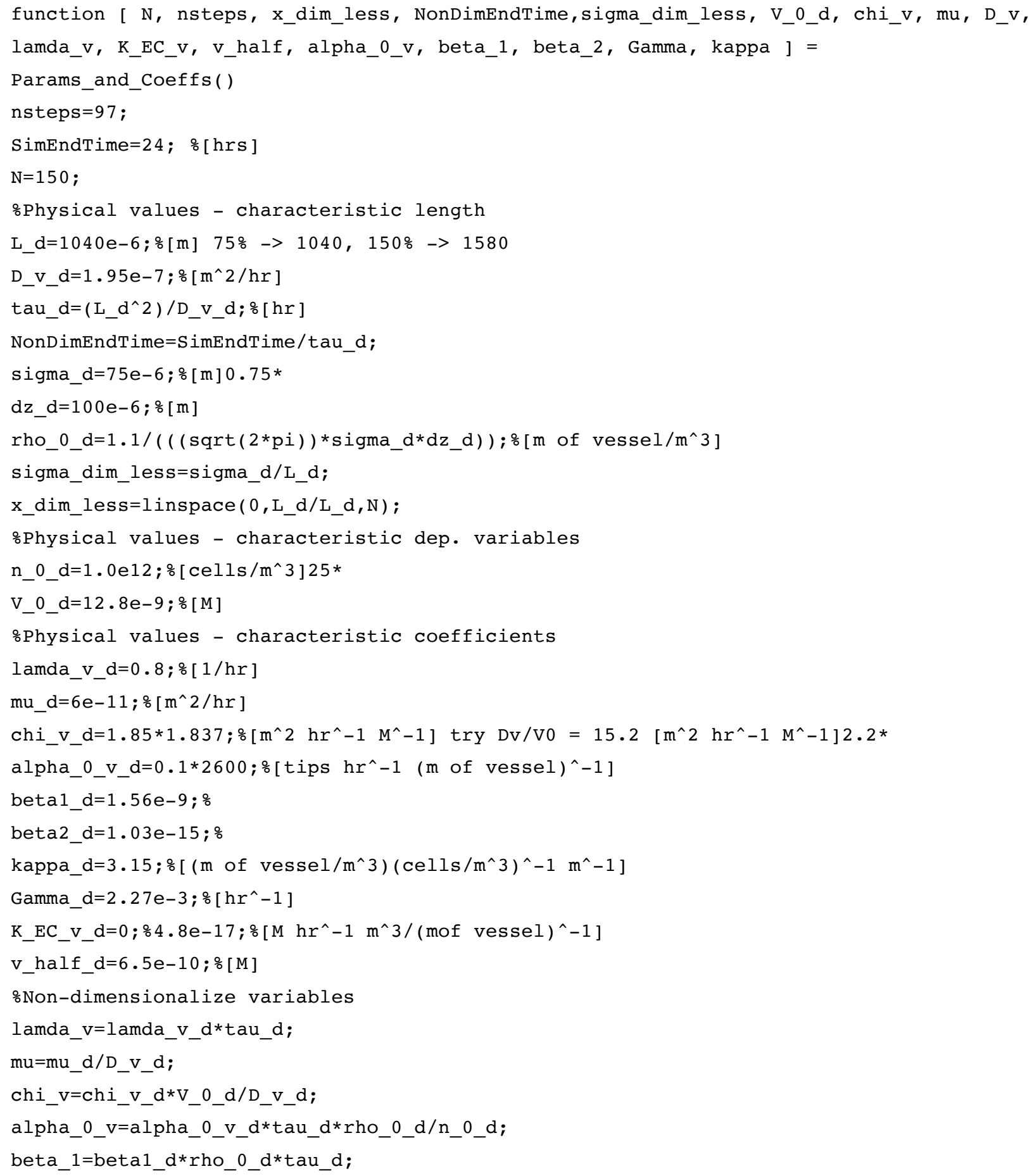




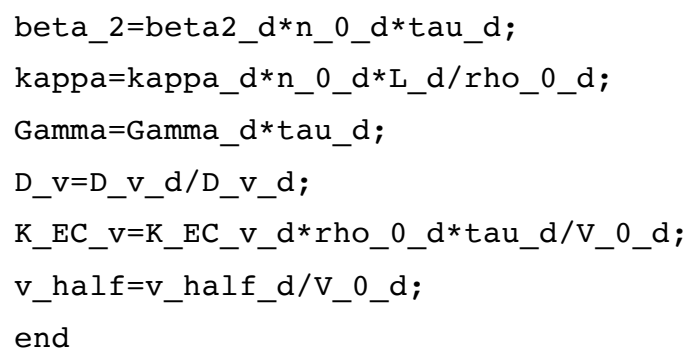

\section{A2.4 Initialization of Dependent Variables - Vessel Model}

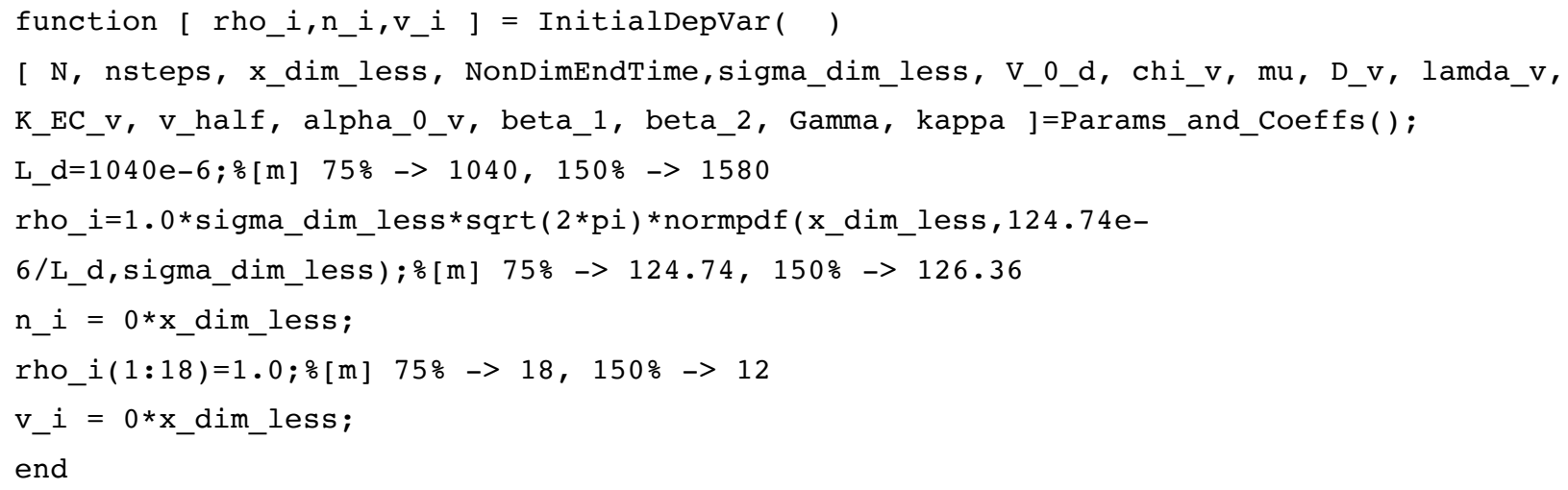

